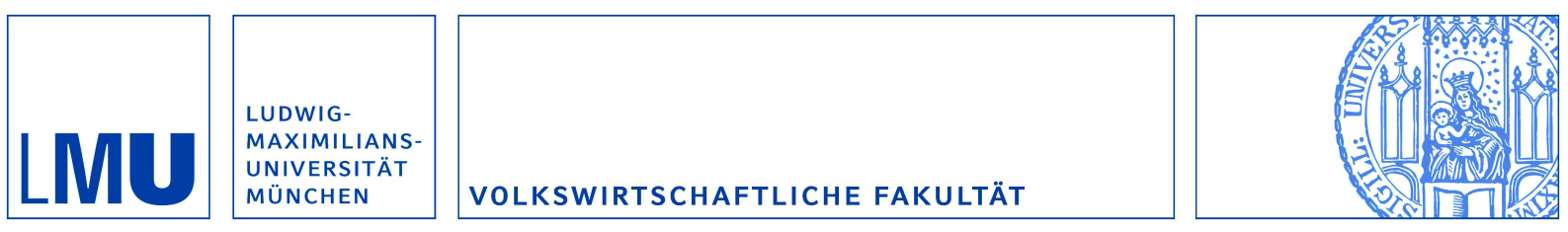

Tarasov, Alexander:

Per Capita Income, Market Access Costs, and Trade Volumes

Munich Discussion Paper No. 2010-27

Department of Economics

University of Munich

Volkswirtschaftliche Fakultät

Ludwig-Maximilians-Universitäł München

Online at https://doi.org/10.5282/ubm/epub. 11494 


\title{
Per Capita Income, Market Access Costs, and Trade Volumes*
}

\author{
Alexander Tarasov ${ }^{\dagger}$ \\ University of Munich
}

December 2009

\begin{abstract}
There is strong empirical evidence that countries with lower per capita income tend to have smaller trade volumes even after controlling for aggregate income. Furthermore, poorer countries do not just trade less, but have a lower number of trading partners. In this paper, I construct and estimate a general equilibrium model of trade that captures both these features of the trade data. There are two novelties in the paper. First, I introduce an association between market access costs and countries' development levels, which can account for the effect of per capita income on trade volumes and explain many zeros in bilateral trade flows. Secondly, I develop an estimation procedure, which allows me to estimate both variable and fixed costs of trade. I find that given the estimated parameters, the model performs well in matching the data. In particular, the predicted trade elasticity with respect to income per capita is close to that in the data.
\end{abstract}

Keywords: export zeros; fixed costs of trade; country extensive margin.

JEL classification: F1

*I am grateful to Kala Krishna and Andrés Rodríguez-Clare for their invaluable guidance and constant encouragement. I also would like to thank Gene Grossman, Ana Cecília Fieler, Manolis Galenianos, Peter Klenow, Vijay Krishna, Andrei Levchenko, Sergey Lychagin, Alexander Monge-Naranjo, Theodore Papageorgiou, Joris Pinkse, James Tybout, Neil Wallace, Stephen Yeaple, and conference participants at 2009 Spring Midwest International Economics meetings and 2009 North American Summer Meeting of the Econometric Society for their helpful comments and discussion. All remaining errors are mine.

${ }^{\dagger}$ Seminar for International Economics, Department of Economics, University of Munich, Ludwigstr. 28, 80539, Munich, Germany. E-mail: alexander.tarasov@lrz.uni-muenchen.de. 


\section{Introduction}

There is strong empirical evidence suggesting that poorer countries (with lower per capita income) trade less even after controlling for aggregate income (see for example Hummels and Klenow (2002)). In addition, poorer countries do not just export or import smaller volumes, but have a fewer number of trading partners. In 1995, for instance, $14 \%$ of all country pairs among the hundred largest countries in terms of GDP did not trade with each other in at least one direction. Furthermore, among those countries, the fifty poorest countries accounted for almost $75 \%$ of zero trade flows in the sample. Hence, the country extensive margin (the number of trading partners) seems to be relevant in explaining the relationship between per capita income and trade volumes. However, even though a number of quantitative trade models capture the phenomenon that poor countries trade less, these models usually focus on explaining aggregate trade volumes and ignore the decomposition of trade volumes into trade margins.

In this paper, I construct and estimate a quantitative general equilibrium model of trade based on Melitz (2003) and Chaney (2008) that captures both the relationship between per capita income and trade volumes and the fact that poorer countries have fewer trading partners. A core element of the model is an association between the costs of access to foreign markets and countries' development levels. This association is motivated by the evidence suggesting that firms in poorer countries may face higher entry barriers to foreign markets (which in turn leads to a larger number of zeros in exports of less developed countries). Indeed, exporting firms may be required to meet certain product standards, quality requirements, and technical regulations imposed by the destination country that are especially restrictive for developing and less developed countries. For instance, studies conducted by the United Nations Conference on Trade and Development find that firms in some developing countries were unable to meet environmental standards and regulations imposed by developed countries, which in turn resulted in considerable export losses (see Chen et al. (2006)). ${ }^{1}$ Poor infrastructure and bureaucracy

\footnotetext{
${ }^{1}$ Quality requirements are another entry barrier for firms from developing and less developed countries. The international management literature emphasizes that one of the key reasons for obtaining quality management certification (ISO 9000) is the requirements of international customers. For instance, Potoski and Prakash (2009) argue that ISO certification is a signal for the quality of a product, which is especially important for developing and less developed countries, as consumers often relate the quality of products to their countries of origin. Meanwhile, the process of certification is costly. It includes both the costs of development and implementation of new production processes satisfying the standards and the costs of certification itself (e.g. the costs of application and documentation review, registrar's visits, etc.). Mersha (1997) documents that achieving the quality management certification is especially complicated in less developed countries (he considers the countries of Sub-Saharan Africa in particular).
} 
also play a role of entry barriers for firms in less developed countries. For example, because of a large number of long administrative procedures and poor logistics services, many firms in less developed countries cannot meet the reliability requirements of foreign partners and, thereby, cannot enter foreign markets (see Nordas et al. (2006)). ${ }^{2}$

I consider an environment where each country is characterized by its population size and development level. Firms vary according to their productivity, which is defined as the product of a firm-specific productivity and a country development level. Exporting firms incur variable and fixed costs of trade. I assume that fixed costs of trade depend on the development level of the exporting country and, thereby, vary across countries. I show that if less developed countries have higher fixed costs of trade relative to other costs (the costs of entry into the industry and fixed costs of selling domestically), then, all else equal, they tend to have smaller trade volumes in equilibrium. ${ }^{3}$ The assumed relationship between fixed costs of trade and countries' development levels also enables us to explain many export zeros in bilateral trade flows. In the same manner as in Helpman et al. (2008), the model is able to predict zero exports from $i$ to $j$ : this happens when there are no firms in country $i$ that are productive enough to find it profitable to export to country $j$. I show that, other things equal, a country with higher fixed costs of trade (relative to other costs) has a higher export productivity cutoff for any export destination. Hence, if less developed countries have higher relative fixed costs of trade, then, other things equal, they tend to have a lower number of export destinations or, in other words, a lower number of trading partners.

To examine how well the model fits the data, I estimate the key parameters of the model using the data for 1995 on bilateral trade flows of the 100 largest countries in terms of total income. The estimation procedure involves minimizing the sum of squared differences between the actual bilateral trade flows and those generated by the model subject to the constraint that the number of zero bilateral trade flows predicted by the model is the same as that in the data. ${ }^{4}$ The novelty of this estimation procedure is that it allows us to estimate both variable

\footnotetext{
${ }^{2}$ According to the Doing Business (2006) report, there is a significant negative correlation between the number of documents required to be filled out before exporting and per capita income of an exporting country: the poorer a country is, the greater the number of documents exporters of that country have to fill out.

${ }^{3}$ As usual in trade theory, relative terms are relevant. For instance, it might be the case that a country faces lower fixed costs of trade in absolute terms but trades less, as fixed costs of trade are higher relative to other costs.

${ }^{4}$ Notice that mismatch is possible. The model can predict some zeros that are not actually observed in the data and vice versa.
} 
and fixed costs of trade. If we drop the constraint on the zeros, variable and fixed costs of trade are not separately identifiable from the bilateral trade data. Furthermore, in contrast to the reduced form estimation (see for example Helpman et al. (2008)), the procedure accounts for the general equilibrium features of the model and enables us to examine how well Melitz-type models perform in explaining the trade data.

After estimating the parameters of the model, I find that there is a strong correlation between fixed costs of trade predicted by the model and countries' development levels. Specifically, less developed countries incur higher fixed costs of trade and, therefore, tend to have smaller trade volumes and a lower number of trading partners. The model performs quite well in matching the data. For instance, in the data, doubling a country's per capita income (controlling for the aggregate income) on average leads to a $19 \%$ increase in trade on average, while the model predicts an increase in trade of $22 \% .^{5}$ Given the estimated parameters, the model is able to explain $35 \%$ of export zeros in the data. In other words, $35 \%$ of the zeros predicted by the model are zeros that are actually observed in the data (the rest is mismatch). ${ }^{6}$ As a comparison, the exact same model but without the assumed variation in fixed costs correctly predicts only $9 \%$ of zeros. Hence, the relationship between fixed costs of trade and countries' development levels matters and helps to explain $26 \%$ of export zeros in the data. The estimation strategy allows us to determine the magnitude of fixed costs of trade. Given the estimated parameters, the aggregate spendings on access to foreign markets constitute on average around half of total export profits. This finding is very similar to that in Eaton et al. (2008) who estimate the market access costs using the data on firm-level trade.

Finally, I examine what the welfare gains are if firms in poor countries incur the same fixed costs of trade as their counterparts in rich countries. To conduct this counterfactual, I set the fixed costs of trade of all countries equal to the estimated value of those in the U.S. (the other parameters of the model are set equal to their estimated values). I find that in this case, welfare in all countries rises with the average percentage change equal to $17 \%$ and larger gains for smaller and poorer countries. In particular, the real income inequality (measured as the ratio of the average real income of the ten richest countries to that of the ten poorest countries) falls by $28 \%$.

The present paper is not the only one to explore the relationship between country's trade

\footnotetext{
${ }^{5}$ By trade, I mean the average between exports and imports.

${ }^{6}$ Remember that the estimation procedure implies that given the estimated parameters, the model predicts the same number of zeros as that in the data.
} 
costs and per capita income. Waugh (2009) considers a general equilibrium model of trade based on Eaton and Kortum (2002). He assumes that variable trade costs are a function of symmetric relationships (e.g., distance, etc.) and an exporter fixed effect. He finds a negative correlation between exporter per capita income and the fixed effect, implying that poor countries face higher variable trade costs than rich countries. In contrast to Waugh (2009), the present model allows us to consider the cross-country variation in both variable and fixed costs of trade. ${ }^{7}$ In particular, I find that the model with the variation only in variable costs (fixed costs are assumed to be identical across countries) performs worse in matching the data than the benchmark model (with the variation only in fixed costs). ${ }^{8}$

A broad strand of the literature considers nonhomotheticity of consumer preferences as a main driving force of the relationship between per capita income and trade volumes. A significant step in this direction is Fieler (2009), who extends the Ricardian model of trade in Eaton and Kortum (2002) by allowing for nonhomothetic preferences and cross-sector differences in production technologies. ${ }^{9}$ The present paper provides another, possibly complimentary, explanation of why poorer countries trade less, which is not based on nonhomotheticity of preferences.

The remainder of the paper is organized as follows. Section 2 introduces the basic concepts of the model and describes the equilibrium. Section 3 presents the main theoretical findings of the model and derives their implications for trade volumes. Section 4 estimates the model and explores its quantitative implications. Section 5 conducts counterfactual analysis. Section 6 examines the quantitative implications of alternative specifications of the model. Section 7 concludes.

\section{Theory}

I consider a variation of the Melitz model extended to a world with $N$ asymmetric countries. Each country is characterized by its population size and development level. The only factor of production is labor, which is inelastically supplied by agents endowed with one unit of labor each. There is a continuum of monopolistically competitive heterogenous firms producing different

\footnotetext{
${ }^{7}$ Since Waugh (2009) considers a perfectly competitive environment, there are no fixed costs of trade in his model.

${ }^{8}$ By the variation in trade costs, I mean the relationship between trade costs and countries' development levels. Specifically, we can assume that variable costs of trade also depend on the exporter development level (see Section 6 for details).

${ }^{9}$ See also Flam and Helpman (1987), Hunter (1991), Markusen (1986), Matsuyama (2000), Mitra and Trindade (2005), and Stokey (1991).
} 
varieties of a differentiated good. Without loss of generality, I assume that agents own equal shares of all firms. ${ }^{10}$ Hence, consumers in country $j$ have identical incomes (which can vary across countries) consisting of labor income $w_{j}$ and the share of firms' profits $\pi_{j}$.

\subsection{Consumption}

I assume that consumers have identical homothetic preferences that take the constant elasticity of substitution (CES) form. In particular, a representative consumer in country $j$ maximizes

$$
Q_{j}=\left(\int_{\omega \in \Omega_{j}} q_{j}^{\frac{\sigma-1}{\sigma}}(\omega) d \omega\right)^{\frac{\sigma}{\sigma-1}}
$$

subject to

$$
\int_{\omega \in \Omega_{j}} p_{j}(\omega) q_{j}(\omega) d \omega=\left(w_{j}+\pi_{j}\right) L_{j}
$$

where $\Omega_{j}$ is the set of available varieties in country $j, q_{j}(\omega)$ is quantity consumed, $p_{j}(\omega)$ is the price of variety $\omega$ in country $j, L_{j}$ is the population size of country $j$, and $\sigma>1$ is the elasticity of substitution between varieties. This maximization problem yields that

$$
q_{j}(\omega)=\left(\frac{p_{j}(\omega)}{P_{j}}\right)^{-\sigma} \frac{\left(w_{j}+\pi_{j}\right) L_{j}}{P_{j}},
$$

where $P_{j}=\left(\int_{\omega \in \Omega_{j}} p_{j}^{1-\sigma}(\omega) d \omega\right)^{\frac{1}{1-\sigma}}$ is the CES price index: i.e., $P_{j} Q_{j}=\left(w_{j}+\pi_{j}\right) L_{j}$.

\subsection{Production}

Production in each country is represented by an average industry with free entry into the industry. To enter the industry in country $i$, ex-ante identical firms have to make sunk investments $f_{e i}$ associated with the creation of a new variety. Once a firm incurs the costs of entry, it obtains a draw $\theta$ of its firm-specific productivity from a distribution $G(\theta)$ with the support on $\left[\theta_{L}, \theta_{H}\right]$. This distribution is common for all firms in all countries. Ex post, firms vary by their productivities, which are the product of a firm-specific productivity $\theta$ and the country development level $Z_{i}$. Hence, both population size $L_{i}$ and development level $Z_{i}$ could affect equilibrium outcomes for country $i$.

The price of variety $\omega$ sold in country $j, p_{j}(\omega)$, is determined by the productivity of the firm producing this variety, its country of origin, and the destination market. Therefore, hereafter

\footnotetext{
${ }^{10} \mathrm{~A}$ more general assumption is that each agent owns a balanced portfolio of shares of all firms. However, due to free entry, the total profits of all firms are equal to zero in equilibrium. This implies that the value of any balanced portfolio is equal to zero. Therefore, to simplify the notation, I assume that agents have equal shares of all firms.
} 
I omit the notation of $\omega$ and use $p_{i j}(\theta)$ instead of $p_{j}(\omega)$. We define $\pi_{i j}(\theta)$ as the variable profits from exporting to country $j$ of the firm, which produces in country $i$ with firm-specific productivity $\theta$. Then,

$$
\pi_{i j}(\theta)=\left(p_{i j}(\theta)-\frac{w_{i}}{Z_{i}} \frac{\tau_{i j}}{\theta}\right)\left(\frac{p_{i j}(\theta)}{P_{j}}\right)^{-\sigma} \frac{\left(w_{j}+\pi_{j}\right) L_{j}}{P_{j}},
$$

where $p_{i j}(\theta)$ solves the following maximization problem:

$$
\max _{p \geq 0}\left(p-\frac{w_{i}}{Z_{i}} \frac{\tau_{i j}}{\theta}\right) p^{-\sigma}
$$

Here $\tau_{i j}$ stands for variable trade costs between country $i$ and $j$, which take Samuelson's iceberg form. I set $\tau_{i i}$ to unity and assume that the triangle inequality holds for any $\tau_{i j}$ : i.e., $\tau_{i j} \leq \tau_{i k} \tau_{k j}$ for any $i, j$, and $k .^{11}$

The pricing rule maximizing (4) is as follows:

$$
p_{i j}(\theta)=\frac{w_{i}}{Z_{i}} \frac{\tau_{i j}}{\theta} \frac{\sigma}{(\sigma-1)} .
$$

Consequently, the variable profits $\pi_{i j}(\theta)$ are given by

$$
\pi_{i j}(\theta)=C\left(\frac{Z_{i}}{w_{i} \tau_{i j}}\right)^{\sigma-1} \frac{\left(w_{j}+\pi_{j}\right) L_{j}}{P_{j}^{1-\sigma}} \theta^{\sigma-1},
$$

where $C=\frac{1}{\sigma}\left(\frac{\sigma-1}{\sigma}\right)^{\sigma-1}$.

To export from country $i$ to country $j$, firms have to pay fixed costs $f_{i j}$ representing the costs of serving market $j .{ }^{12}$ The presence of fixed costs implies that not all firms find it profitable to export or sell at home. Firms with relatively low productivities exit because of negative potential profits. In particular, firms located in country $i$ with $\theta<\theta_{i j}$ decide not to export to country $j$, where the cutoff $\theta_{i j}$ is determined by

$$
\pi_{i j}\left(\theta_{i j}\right)=f_{i j}
$$

The last expression implies that the cutoff $\theta_{i j}$ is given by

$$
\theta_{i j}=\frac{w_{i}}{Z_{i}} \tau_{i j}\left(\frac{1}{C} \frac{P_{j}^{1-\sigma}}{\left(w_{j}+\pi_{j}\right) L_{j}}\right)^{\frac{1}{\sigma-1}} f_{i j}^{\frac{1}{\sigma-1}} .
$$

\footnotetext{
${ }^{11}$ The triangle inequality guarantees that it is cheaper to deliver goods from country $i$ directly to country $j$, rather than to use another country as an intermediary.

${ }^{12}$ The fixed costs of selling at home are $f_{i i}$.
} 
Higher $\theta_{i j}$ means that fewer firms based in country $i$ find it profitable to export to country $j$. In particular, if $\theta_{i j}>\theta_{H}$, then no firm exports from country $i$ to country $j$ resulting in zero exports from $i$ to $j$.

We define $r_{i j}(\theta)$ as the revenues received from exporting to country $j$ by a firm with $\theta$ located in country $i$. Then,

$$
r_{i j}(\theta)=\sigma C\left(\frac{Z_{i}}{w_{i} \tau_{i j}}\right)^{\sigma-1} \frac{\left(w_{j}+\pi_{j}\right) L_{j}}{P_{j}^{1-\sigma}} \theta^{\sigma-1} .
$$

As a result, the total value of exports from country $i$ to country $j, X_{i j}$, is given by

$$
X_{i j}=M_{e i} \int_{\theta_{i j}}^{\theta_{H}} r_{i j}(\theta) d G(\theta),
$$

where $M_{e i}$ is the mass of entrants into the industry. ${ }^{13}$ Since there are $M_{e i} d G(\theta)$ firms with productivity $\theta$ in country $i$, the measure of available varieties in country $j$ is equal to:

$$
\mu\left(\Omega_{j}\right)=\sum_{i=1}^{N} M_{e i}\left(1-G\left(\theta_{i j}\right)\right)
$$

\subsection{Market Access Costs and Costs of Entry}

I assume that the fixed costs of serving a certain market are subdivided into two parts: costs directly associated with serving the market (for instance, the construction of facilities) and costs associated with access to the market (for instance, satisfying product standards and quality requirements of the destination country). Furthermore, I assume that domestic firms pay only the former, while foreign firms pay both. Hence, the functional form for the fixed costs of exporting is as follows:

$$
f_{i j}=\left\{\begin{array}{l}
w_{i} f_{d}+w_{i} \frac{f_{x}}{Z_{i}^{\delta}}, \text { if } j \neq i, \\
w_{i} f_{d}, \quad \text { otherwise, }
\end{array}\right.
$$

where $f_{d}$ and $f_{x}$ are common for all countries. The parameter $\delta$ describes how the country development level $Z_{i}$ affects the fixed costs of exporting. If $\delta$ is greater (less) than zero, then more developed countries use fewer (more) units of labor to access foreign markets.

\footnotetext{
${ }^{13}$ Note that the mass of firms based in country $i$ and serving market $j$ is equal to $M_{i j}=M_{e i}\left(1-G\left(\theta_{i j}\right)\right)$. In this manner, the expression (9) can be rewritten as

$$
X_{i j}=M_{i j} \int_{\theta_{i j}}^{\theta_{H}} r_{i j}(\theta) d \frac{G(\theta)}{1-G\left(\theta_{i j}\right)},
$$

where $\frac{G(\theta)}{1-G\left(\theta_{i j}\right)}$ is the distribution of firm-specific productivities conditional on $\theta \geq \theta_{i j}$.
} 
This way of representing fixed costs of trade is one of the key points in the paper. Melitz (2003) considers trade between symmetric countries, so fixed costs are the same for all countries. Chaney (2008) explores the Melitz framework with many asymmetric countries. However, he does not impose any particular relationship or structure on fixed costs of trade.

In the present paper, it is assumed that fixed costs of exporting depend only on exporter characteristics. Meanwhile, Arkolakis (2008) and Eaton et al. (2008) argue that the costs of access to foreign markets depend on the characteristics of the destination market as well. For instance, Arkolakis (2008) relates fixed costs of exporting to product advertising requiring labor services from both source and destination countries. In Section 6, I consider alternative specifications of the model, which include the dependence of fixed costs on the importer development level.

Finally, I assume that the costs of entry into the industry are given by

$$
f_{e i}=w_{i} f_{e} \text { for all } i
$$

where $f_{e}$ is common for all countries.

\subsection{Equilibrium}

Given the set of parameters $\left\{f_{d}, f_{x}, \delta, f_{e}, \tau_{i j}, \sigma, G(\cdot), Z_{i}, L_{i}\right\}_{i, j=1 . . N}$, the equilibrium in the model is defined by $\left\{p_{i j}(\theta), P_{i}, M_{e i}, \theta_{i j}, w_{i}\right\}_{i, j=1 . . N}$ such that

1) $\left\{p_{i j}(\theta)\right\}_{i, j=1 . . N}$ are determined by the firm maximization problem (see (5)).

2) $\left\{P_{i}\right\}_{i=1 . . N}$ satisfy the following equation:

$$
P_{i}=\left(\int_{\omega \in \Omega_{i}} p_{i}^{1-\sigma}(\omega) d \omega\right)^{\frac{1}{1-\sigma}}
$$

which is equivalent to

$$
P_{i}^{1-\sigma}=\sum_{j=1}^{N} M_{e j} \int_{\theta_{j i}}^{\theta_{H}} p_{j i}^{1-\sigma}(\theta) d G(\theta)
$$

3) Expected profits of a given firm are equal to zero, meaning that

$$
f_{e i}=\sum_{j=1}^{N} \operatorname{Pr}\left(\theta \geq \theta_{i j}\right) E\left(\left(\pi_{i j}(\theta)-f_{i j}\right) \mid \theta \geq \theta_{i j}\right) .
$$

4) $\left\{\theta_{i j}\right\}_{i, j=1 . . N}$ satisfy the zero profit condition (see (7)).

5) Trade is balanced, implying that

$$
\sum_{j=1}^{N} M_{e i} \int_{\theta_{i j}}^{\theta_{H}} r_{i j}(\theta) d G(\theta)=\sum_{j=1}^{N} M_{e j} \int_{\theta_{j i}}^{\theta_{H}} r_{j i}(\theta) d G(\theta) .
$$


Note that the set $\left\{w_{i}, P_{i}, M_{e i}\right\}_{i=1 . . N}$ is sufficient to determine all other endogenous variables in the model such as $p_{i j}(\theta), \pi_{i j}(\theta), r_{i j}(\theta)$, and $\theta_{i j}$. This implies that to find the equilibrium in the model, we need to find the set $\left\{w_{i}, P_{i}, M_{e i}\right\}_{i=1 . . N}$, which satisfies the following system of equations:

$$
\left\{\begin{array}{c}
P_{i}^{1-\sigma}=\sum_{j=1}^{N} M_{e j} \int_{\theta_{j i}}^{\theta_{H}} p_{j i}^{1-\sigma}(\theta) d G(\theta), \\
f_{e i}=\sum_{j=1}^{N} \operatorname{Pr}\left(\theta \geq \theta_{i j}\right) E\left(\left(\pi_{i j}(\theta)-f_{i j}\right) \mid \theta \geq \theta_{i j}\right), \\
\sum_{j=1}^{N} M_{e i} \int_{\theta_{i j}}^{\theta_{H}} r_{i j}(\theta) d G(\theta)=\sum_{j=1}^{N} M_{e j} \int_{\theta_{j i}}^{\theta_{H}} r_{j i}(\theta) d G(\theta),
\end{array}\right.
$$

where $p_{i j}(\theta), \pi_{i j}(\theta), r_{i j}(\theta)$, and $\theta_{i j}$ are expressed in terms of $\left\{w_{i}, P_{i}, M_{e i}\right\}_{i=1 . . N}$ and the parameters of the model. Thus, we have the system of $3 N$ equations with $3 N$ unknowns, $\left\{w_{i}\right.$, $\left.P_{i}, M_{e i}\right\}_{i=1 . . N}$. Consequently, taking $w_{N}$ as numeraire, we can solve the system and find the endogenous variables for any given set of the parameters.

\section{Per Capita Income and Trade Volumes}

In the equilibrium, the total income of country $i$ is given by $w_{i} L_{i}$, where $w_{i}$ is a function of both $Z_{i}$ and $L_{i}$ (and the other parameters of the model). ${ }^{14}$ It is straightforward to show that all else equal, more developed countries (with higher $Z_{i}$ ) tend to have higher total income. This in turn means that there is a positive correlation between per capita income $w_{i}$ and development level $Z_{i}$

In this section, I compare trade volumes of two countries with identical total incomes but different components, per capita income and population size, within a given equilibrium. This way of conducting comparative statics corresponds to a cross-country comparison in the data. In particular, I consider such an equilibrium that there are two countries, 1 and 2; which are identical in every way except for $Z_{i}$ and $L_{i}$. Furthermore, I assume that $Z_{1}, Z_{2}, L_{1}$, and $L_{2}$ are such that $Z_{1}>Z_{2}, L_{1}<L_{2}$, and $w_{1} L_{1}=w_{2} L_{2}$ in the equilibrium. ${ }^{15}$ In this way, I restrict countries 1 and 2 to have the same size of economy but different per capita incomes: country 1 is richer and smaller, while country 2 is poorer and larger.

To capture only the effects of $Z_{i}$ and $L_{i}$ on trade volumes, I assume that the countries are geographically symmetric and have identical trading partners. Namely, I assume that $\tau_{1 j}=\tau_{2 j}$

\footnotetext{
${ }^{14}$ Recall that free entry into the industry leads to zero total profits: i.e., $\pi_{i}=0$ for all $i=1 . . N$. This means that the total income in country $i$ equals to $w_{i} L_{i}$.

${ }^{15}$ Note that since higher $Z_{i}$ implies higher $w_{i}$, we can always find such values of $Z_{1}$ and $Z_{2}$ that $w_{1} L_{1}=w_{2} L_{2}$ in the equilibrium.
} 
and $\tau_{j 1}=\tau_{j 2}$ for all $j>2$. In addition, I assume that trade costs between country 1 and 2 are so high that the countries do not trade with each other in the equilibrium. For instance, we can think that country 1 is located at the North Pole, country 2 is located at the South Pole, while the rest of the world is located along the equator. Note that this approach of analyzing the effects of $Z_{i}$ and $L_{i}$ is equivalent to a standard comparative statics exercise (where we compare equilibrium outcomes before and after a change in a parameter) applied to a small open economy.

I show that if $\delta$ is greater than zero, then the richer country has greater trade volumes in the equilibrium. The intuition behind this result goes as follows. As $Z_{1}>Z_{2}$, for all $j>2$,

$$
\frac{f_{1 j}}{f_{e 1}}<\frac{f_{2 j}}{f_{e 2}} .
$$

In words, it is relatively less expensive to export than to create a new variety in country 1 . As a result, country 1 has lower mass of entrants into the industry but a higher number of exporting firms relative to the mass of entrants. Furthermore, for all $j>2$,

$$
\frac{f_{1 j}}{f_{11}}<\frac{f_{2 j}}{f_{22}} .
$$

That is, country 1 has lower fixed costs of trade relative to fixed costs of selling domestically. This implies that country 1 has a higher number of exporting firms not only relative to the mass of entrants, but also relative to the number of firms serving the domestic market. This in turn leads to greater trade volumes in country $1 .^{16}$

Notice that as usual in trade theory, relative terms matter. It might be the case that a country faces lower fixed costs of trade in absolute terms but trades less, as fixed costs of trade are higher relative to the other costs. While the intuition is straightforward, the proof is quite complex. This is due to the difficulty of obtaining analytical results in the presence of asymmetries in Melitz type models. To prove this claim, I make two assumptions.

Assumption 1: $\frac{\theta^{\sigma} g(\theta)}{\int_{\theta}^{\theta} H t^{\sigma-1} d G(t)}$ is weakly increasing in $\theta$, where $g(\theta)$ is the density function associated with $G(\theta)$.

\footnotetext{
${ }^{16}$ It might seem that the inequality in (14) is sufficient for country 1 to have greater trade volumes and (13) is redundant. However, it is not true. Suppose that fixed costs of selling domestically are sufficiently low and all entrants in both countries find it profitable to sell at home. That is, the equilibrium values of $\theta_{11}$ and $\theta_{22}$ are less than $\theta_{L}$. Then, having a higher number of exporting firms relative to the number of firms selling at home is equivalent to having a higher number of exporting firms relative to the mass of entrants. Hence, we need (13) to show that country 1 has greater trade volumes. Moreover, by continuity, this example can be extended to the case when the equilibrium values of $\theta_{11}$ and $\theta_{22}$ lie in some right neighborhood of $\theta_{L}$.
} 
This assumption has a natural interpretation. It implies that $g(\theta)$ does not decrease too fast; i.e., the probability of getting higher values of $\theta$ does not decrease too fast with $\theta$. For instance, a truncated Pareto distribution or a power distribution satisfies this condition.

Assumption 2: Trade costs are so high that $\theta_{1 j} \geq \theta_{11}$ and $\theta_{2 j} \geq \theta_{22}$ for all $j>2$.

This is a standard assumption in trade literature, saying that exporting firms serve the home market as well. It is consistent with empirical evidence: only a small fraction of firms export and those that export also sell domestically.

Proposition 1 If $\delta>0$ and Assumptions 1 and 2 hold, then country 1 has greater trade volumes in equilibrium.

Proof. See the proof in Appendix $A$.

Note that in general, we can assume that the costs of entry into the industry and selling at home also depend on the country development level. This would not change the main findings above (except the condition on $\delta$ ), as we need differences in relative terms. In the paper, I do not introduce this dependence, as it is not identifiable from the trade data.

\section{Estimation}

To understand the contribution of the imposed association between the market access costs and the development levels in explaining the trade data, I estimate the key parameters of the model. In the estimation procedure, I use data on total income, population, bilateral trade flows, and cultural and geographical barriers between country pairs for 1995. I consider the sample of the hundred largest countries in terms of GDP, for which the data sets are complete. ${ }^{17}$ These countries account for $91.6 \%$ of world trade in 1995. I assume that the other countries do not exist (these hundred countries constitute the entire world). Exports to non-existent countries are considered as domestic sales.

Data on total income and population are taken from the World Bank (2007). Table 13 reports the list of the countries in the sample arranged by the size of GDP. Data on bilateral

\footnotetext{
${ }^{17}$ Because of entrepot trade, which is not captured by my model, I consider Belgium and Luxemburg as well as China, Hong-Hong, and Macao as one country. There are two outliers in the sample: Malaysia and Singapore. These countries have trade volumes greater than their total incomes (due to entrepot trade). However, their effect on the parameter estimates is negligible. Removing these countries from the sample does not change the estimation results.
} 
trade flows comes from the United Nation Statistics Division (2007). ${ }^{18}$ In constructing bilateral trade flows, I follow Feenstra et al. (2005). As a measure of trade volumes between countries, I use trade values reported by the importing country, as they tend to be more precise than those reported by the exporter. However, if an importer report is not available, I use the corresponding exporter report instead. There are 1399 export zeros in the sample, which constitutes $14 \%$ of the total number of bilateral trade flows.

As potential trade barriers, I consider distance, the effects of common border and language, and the impact of membership in free trade areas. ${ }^{19}$ Hence, for each country pair we need data on whether these countries have a common language or share a common border plus data on distance between them. ${ }^{20}$ I take these data sets from the Centre d'Etudes Prospectives et d'Informations Internationales (2005). In addition, I use the data on whether the pair of countries belongs to the North American Trade Agreement (NAFTA) or the European Union $(\mathrm{EU})$.

Figure 1 displays the relationship in the data between the log of trade volumes (the average between exports and imports) and the $\log$ of GDP. As is evident from the figure, there is a strong positive correlation between countries' trade volumes and total income. This is in line with the previous empirical studies on the gravity equation. Figure 2 depicts the relationship between the residuals and countries' logs of income per capita and population size. As it is inferred from the figure, there is a significant positive correlation between the residuals and income per capita. This suggests that conditional on GDP, richer countries trade more.

\subsection{Parametrization}

To estimate the model, we need to parametrize the distribution of firm-specific productivity draws $G(\theta)$ and variable trade $\operatorname{costs} \tau_{i j}$. In parametrizing $G(\theta)$, I follow a number of studies using a truncated Pareto distribution to describe the distribution of firm productivities. ${ }^{21}$ In

\footnotetext{
${ }^{18}$ An alternative source for data on trade flows is the NBER-UN data set constructed by Feenstra et al. (2005). However, this data set includes only trade flows in a certain category with values greater than $\$ 100.000$ per year. When aggregating, this may potentially lead to underestimation of aggregate exports and imports and overestimation of the number of zero trade flows.

${ }^{19}$ Many other variables (for instance, religion or colonial origin) can be used as additional measures of trade barriers between countries. However, to reduce the number of parameters I need to estimate, I consider only language, border, distance, and membership in free trade areas.

${ }^{20}$ By distance between two countries, I mean the distance between the main cities in the countries. Usually, the main city is the capital. However, in some cases, the capital is not populated enough to serve a role of the economic center of the country. In these cases, the most populated city represents the country.

${ }^{21}$ See e.g. Helpman et al. (2008) or Johnson (2007).
} 
particular, I assume that

$$
G(\theta)=\frac{\frac{1}{\theta_{L}^{k}}-\frac{1}{\theta^{k}}}{\frac{1}{\theta_{L}^{k}}-\frac{1}{\theta_{H}^{k}}} \text { on }\left[\theta_{L}, \theta_{H}\right],
$$

where $\infty \geq \theta_{H}>\theta_{L}>0$ and $k>\sigma-1$. The last condition guarantees that in the case when $\theta_{H}=\infty$, the integral $\int_{\theta_{i j}}^{\theta_{H}} \theta^{\sigma-1} d G(\theta)$ exists.

I assume the following functional form for variable trade costs:

$$
\tau_{i j}=1+\gamma_{0} D_{i j}^{\gamma_{1}} \gamma_{2}^{B_{i j}} \gamma_{3}^{L N G_{i j}} \gamma_{4}^{N A F_{i j}} \gamma_{5}^{E U_{i j}} \text { for } j \neq i
$$

where $\left\{\gamma_{0}, \gamma_{1}, \gamma_{2}, \gamma_{3}, \gamma_{4}, \gamma_{5}\right\}$ is the set of parameters describing variable costs of trade. $D_{i j}$ is the distance between countries $i$ and $j, B_{i j}$ and $L N G_{i j}$ are dummy variables for common border and language, and $N A F_{i j}$ and $E U_{i j}$ are dummy variables for whether countries $i$ and $j$ are members of NAFTA or EU, respectively. For instance, if $\gamma_{2}$ is less (greater) than one, then sharing a common border reduces (increases) the costs of trade between countries.

Hence, the set of parameters of the model is given by

$$
\left\{\gamma_{0}, \gamma_{1}, \gamma_{2}, \gamma_{3}, \gamma_{4}, \gamma_{5}, f_{x}, \delta, f_{e}, f_{d}, \sigma, k, \theta_{L}, \theta_{H}\right\}
$$

Note that a number of parameters in (17), namely $\left\{f_{e}, f_{d}, \sigma, k, \theta_{L}, \theta_{H}\right\}$, are not identifiable from the trade data (i.e., the fit of the data does not vary as you change them). Therefore, I fix these parameters at values consistent with other work.

In fixing $\sigma$, I follow the results in the previous studies estimating the elasticity of substitution. Bernard et al. (2003) argue that $\sigma$ equal to 3.8 captures the export behavior of the U.S. plants best. Broda and Weinstein (2006) estimate the elasticity of substitution for different aggregation levels. In period 1990-2001 for SITC-3 aggregation level, the estimates vary from 1.2 (thermionic, cold cathode, photocathode valves, etc.) to 22.1 (crude oil from petroleum or bituminous minerals) with the mean equal to 4. The number obtained in Bernard et al. (2003) is close to the mean of the estimates in Broda and Weinstein (2006). Following their results, I set $\sigma$ equal to 3.8 .

The distribution of productivity draws in (15) is characterized by parameters $\theta_{L}, \theta_{H}$, and $k$. I normalize $\theta_{L}$ to unity. In many studies, to simplify analytical derivations $\theta_{H}$ is set to infinity. ${ }^{22}$ However, setting $\theta_{H}$ to infinity implies that there always exist some relatively productive firms finding it profitable to export to any country. This means that the model will not generate

\footnotetext{
${ }^{22}$ See for example Chaney (2008).
} 
Table 1: The Values Assigned to the Unidentifiable Parameters

\begin{tabular}{lr}
\hline \hline \multicolumn{1}{c}{ Parameter } & Value \\
\hline Elasticity of substitution, $\sigma$ & 3.8 \\
Shape parameter, $k$ & 3.4 \\
Lower support, $\theta_{L}$ & 1 \\
Upper support, $\theta_{H}$ & 20 \\
Fixed costs of selling at home, $f_{d}$ & 0 \\
Costs of entry, $f_{e}$ & 1 \\
\hline \hline
\end{tabular}

export zeros, which is at odds with the data. In the paper, I set $\theta_{H}$ equal to 20 . On the one hand, finite $\theta_{H}$ allows for zero bilateral flows. On the other hand, there is not much difference in terms of the statistics of the productivity distribution (such as average, variance, etc.) between $\theta_{H}=20$ and $\theta_{H}=\infty$. That is, the choice of $\theta_{H}$ is mainly consistent with the previous studies and allows for export zeros. The shape parameter $k$ determines the behavior of the tail of the firm-specific productivity distribution. Following Ghironi and Melitz (2004) and Bernard et al. (2007), I set $k$ equal to 3.4 .

Following Helpman et al. (2008), I set $f_{d}$ equal to zero so that there are no fixed costs of selling domestically, implying that all entering firms serve the home market. Finally, as changes in the parameter $f_{e}$ only rescale the mass of entrants into the industry and have no impact on trade volumes, I normalize $f_{e}$ to unity. ${ }^{23}$

Hereafter, I assume that the set of parameters $\left\{f_{e}, f_{d}, \sigma, k, \theta_{L}, \theta_{H}\right\}$ is fixed at the values reported in Table 1. In Appendix B, I do several robustness checks by trying some other parameter values. I find that changes in the values do not substantially alter the quantitative implications of the model.

\subsection{Estimation Procedure}

The rest of the parameters is given by $\Theta=\left\{\gamma_{0}, \gamma_{1}, \gamma_{2}, \gamma_{3}, \gamma_{4}, \gamma_{5}, f_{x}, \delta\right\}$. To estimate these parameters, I use a restricted non-linear least squares procedure. For given $\Theta$ and $\left\{Z_{i}, L_{i}\right\}_{i=1 . . N}$, we can solve the system of equations (12) and find the equilibrium values of $\left\{w_{i}, P_{i}, M_{e i}\right\}_{i=1 . . N}$

\footnotetext{
${ }^{23}$ The condition (28) implies that any changes in $f_{i j}$ and $f_{e i}$ keeping $\frac{f_{i j}}{f_{e i}}$ fixed for all $j$ do not affect the cutoffs $\theta_{i j}$ and, therefore, trade volumes.
} 
(notice that if we know $\Theta$, we can construct $\left\{\tau_{i j}\right\}_{i, j=1 . . N}$ using (16)). Let $X_{i j}(Z, L, \Theta)$ denote the value of exports from country $i$ to $j$ generated by the model conditional on $\Theta,\left\{Z_{i}, L_{i}\right\}_{i=1 . . N}$, and the corresponding equilibrium values of $\left\{w_{i}, P_{i}, M_{e i}\right\}_{i=1 . . N}$ (here $Z=\left\{Z_{i}\right\}_{i=1 . . N}$ and $\left.L=\left\{L_{i}\right\}_{i=1 . . N}\right)$. In words, if we know the parameters of the model and the exogenous variables $Z$ and $L$, we can solve for the equilibrium and construct the corresponding bilateral trade flows. To estimate $\Theta$, I solve the following minimization problem:

$$
\min _{\Theta} \sum_{i, j: i \neq j}\left(X_{i j}^{o}-X_{i j}(Z, L, \Theta)\right)^{2}
$$

subject to

$$
\Psi(Z, L, \Theta)=0
$$

where $X_{i j}^{o}$ is the value of exports from $i$ to $j$ observed in the data. $\Psi(Z, L, \Theta)$ stands for the difference between the number of zeros predicted by the model (given $\Theta$ and $\left\{Z_{i}, L_{i}\right\}_{i=1 . . N}$ ) and the actual number of zero bilateral trade flows in the data (the "actual" zeros). ${ }^{24}$ This estimation technique also allows to account for the general equilibrium features of the model (including the effects of free entry into the industry) and to use the information contained in export zeros. The restriction (19) is imposed for identification purposes. In particular, the variable and fixed costs of trade are not separately identifiable from just bilateral trade data. Any changes in $f_{x}$ can be offset by proper changes in $\left\{\gamma_{0}, \gamma_{1}, \gamma_{2}, \gamma_{3}, \gamma_{4}, \gamma_{5}, \delta\right\}$ without affecting the value of the objective function in (18).

The estimation procedure discussed above is based on the fact that we know the values of $\left\{Z_{i}, L_{i}\right\}_{i=1 . . N}$. While for $\left\{L_{i}\right\}_{i=1 . . N}$ we can use the data on population size in the countries,

\footnotetext{
${ }^{24}$ The estimation procedure implies that the model fits just the number of zeros. However, it is possible that the model generates zeros that are not actually observed in the data and vice versa. Therefore, we can decompose $\Psi(Z, L, \Theta)$ into the sum of two terms:

$$
\Psi(Z, L, \Theta)=\Psi_{T}(Z, L, \Theta)+\Psi_{F}(Z, L, \Theta) .
$$

In $(20), \Psi_{T}(Z, L, \Theta)$ is the difference between the number of correctly predicted zeros (zeros predicted by the model and observed in the data) and the number of "actual" zeros, while $\Psi_{F}(Z, L, \Theta)$ is the mismatch (zeros that are predicted by the model but not observed in the data). Hence, the restriction (19) implies that equal weights are attached to $\Psi_{T}(Z, L, \Theta)$ and $\Psi_{F}(Z, L, \Theta)$. In Appendix $C$, I examine alternative restrictions in the minimization problem. In particular, I consider the following restriction:

$$
(1-\varepsilon) \Psi_{T}(Z, L, \Theta)+\varepsilon \Psi_{F}(Z, L, \Theta)=0,
$$

where $\varepsilon \in[0,1]$ represents a certain weight attached to the mismatch. For instance, if $\varepsilon$ is equal to zero, then the mismatch is of no importance and, as a result, the model predicts all the zeros in the data plus some others. If $\varepsilon$ is equal to unity, then we only care about the mismatch. All zeros generated by the model match the zeros in the data. Notice that if $\varepsilon$ is equal to 0.5 , then we obtain the restriction in (20). In the Appendix, I consider $\varepsilon$ equal to 0.25 and 0.75 . I find that changes in $\varepsilon$ affect the implications of the model regarding zeros only (see Appendix $C$ for details).
} 
$\left\{Z_{i}\right\}_{i=1 . . N}$ are not observable. To resolve this problem, I use the data on per capita income levels to reconstruct $\left\{Z_{i}\right\}_{i=1 . . N}$. Specifically, from the equilibrium conditions (12) we have that $w=w(Z, L, \Theta)$, where $w=\left\{w_{i}\right\}_{i=1 . . N}$. This implies that we can express $Z$ in terms of $w, L$, and the parameters $\Theta$. That is, we can invert the function $w(Z, L, \Theta)$ and obtain $Z=Z(w, L, \Theta) .{ }^{25}$ In the model, $w_{i}$ is equal to per capita income in country $i$, which is observed in the data. Hence, using the data for $\left\{w_{i}\right\}_{i=1 . . N}$ we can reconstruct $\left\{Z_{i}\right\}_{i=1 . . N}$. In this case, the minimization problem can be rewritten as follows:

$$
\min _{\Theta} \sum_{i, j: i \neq j}\left(X_{i j}^{o}-X_{i j}(Z(w, L, \Theta), L, \Theta)\right)^{2}
$$

subject to

$$
\Psi(Z(w, L, \Theta), L, \Theta)=0
$$

Note that the structure of the equations in (12) is nonlinear. This implies that the function $w(Z, L, \Theta)$ is not necessarily one-to-one. For instance, several different values of $Z$ may lead to the same value of $w$. However, no such examples occur in the numerical analysis I conduct in the paper.

Notice that in the model, $L_{i}$ can be interpreted not only as population size in country $i$, but also as the size of labor force in that country. In the paper, I use the data on population sizes to construct $\left\{L_{i}\right\}_{i=1 . . N}$, while I also estimate the model using the data on the size of labor force in the countries. I find that the results do not substantially differ from those obtained in the paper.

In Appendix $D$, as a robustness check I consider alternative estimation procedures such as non-linear least deviations and non-linear least squares applied to logarithms rather than levels. I find that these estimation procedures yield similar predictions as the procedure used in the paper.

\subsection{Results}

As a measure of the explanatory power of the model, I use

$$
R^{2}=1-\frac{\sum_{i, j: i \neq j}\left(X_{i j}^{o}-X_{i j}(Z(w, L, \Theta), L, \Theta)\right)^{2}}{\sum_{i, j: i \neq j}\left(X_{i j}^{o}\right)^{2}} .
$$

The explanatory power is $100 \%$, if we are able to fit perfectly all bilateral trade flows: i.e., $\sum_{i, j: i \neq j}\left(X_{i j}^{o}-X_{i j}(Z(w, L, \Theta), L, \Theta)\right)^{2}=0$.

\footnotetext{
${ }^{25} Z_{U S A}$ is normalized to unity.
} 
Table 2 reports the results obtained from solving (21) subject to (22). ${ }^{26}$ The explanatory power of the model is $81 \%$. Like in traditional estimates of the gravity equation, the results show that country $i$ and $j$ trade more if they are closer to each other, have a common border, share a common language, or belong to the same regional trade agreement (NAFTA or EU). The estimated value of $\delta$ is 0.67 , implying a strong correlation between country development level and market access costs. More developed countries tend to have lower fixed costs of exporting relative to the other costs.

To compare the quantitative implications of the model with the data, I run the following regression (robust standard errors in parentheses):

$$
\ln \frac{T_{i}}{T_{i}(\hat{\Theta})}=\underset{(0.09)}{-1.23}+\underset{(0.03)}{0.16} \ln G D P_{i}-\underset{(0.04)}{0.04} \ln \frac{G D P_{i}}{L_{i}}
$$

where $T_{i}$ is the actual trade volumes of country $i$ and $T_{i}(\hat{\Theta})$ is the volumes of trade generated by the model given the estimated values of the parameters (see Table 2). As we can see from (23), the model captures the effect of per capita income on trade volumes (conditional on total income) quite well. The corresponding coefficient is not significantly different from zero. Meanwhile, the estimates in (23) suggest that the model somewhat underestimates trade volumes of large population countries. Table 3 reports the elasticities of trade with respect to total and per capita incomes observed in the data and generated by the model (the first and second columns, respectively). In the data, doubling a country income per capita (keeping the total income unaltered) leads on average to an increase in trade volumes of $19 \%$ and doubling a country population size raises trade volumes by $85 \%$. The model predicts a rise in trade volumes of $22 \%$ and $69 \%$, respectively.

Recall that the restriction (22) in the estimation procedure implies that the number of zero bilateral trade flows generated by the model is the same as that in the data. As it was discussed above, mismatch is possible. I find that the model explains $35 \%$ of the zeros in the data. That is, $35 \%$ of zeros generated by the model match the zeros observed in the data, while the rest is mismatch. The key point is that the model underestimates trade volumes of large population countries. As a result, it generates a number of "false" zeros among countries with large population and does not predict many zeros in the data among small population countries. Notice that the estimated association between a country development level and fixed costs of trade helps to explain many zeros in the data. In the next subsection, I estimate a variation of

\footnotetext{
${ }^{26} \mathrm{I}$ do not report the asymptotic errors, as it is extremely hard to explore the asymptotic properties of the obtained estimate.
} 
Table 2: Parameter Estimates

\begin{tabular}{c|c|c|c|c|c|c|c||c}
\hline \hline$\gamma_{0}$ & $\gamma_{1}$ & $\gamma_{2}$ & $\gamma_{3}$ & $\gamma_{4}$ & $\gamma_{5}$ & $f_{x}$ & $\delta$ & $R^{2}$ \\
\hline 0.49 & 0.14 & 0.76 & 0.97 & 0.78 & 0.94 & 2.15 & $\mathbf{0 . 6 7}$ & $81 \%$ \\
\hline \hline
\end{tabular}

the model when $\delta$ is equal to zero: i.e., fixed costs of trade (in terms of labor units) are identical across the countries. I find that in this case, the mismatch constitutes $91 \%$.

The estimated values of the parameters also allow us to determine the magnitude of fixed costs of trade. For each country I construct the ratio of the aggregate fixed costs of exporting to the aggregate export profits, which is given by

$$
F C_{R i}=\frac{M_{e i} \sum_{j \neq i}^{N}\left(1-G\left(\theta_{i j}\right)\right) f_{i j}}{M_{e i} \sum_{j \neq i}^{N} \int_{\theta_{i j}}^{\theta_{H}} \pi_{i j}(\theta) d G(\theta)}
$$

The ratios vary from 0.32 (for Iceland) to 0.64 (for India) with the mean equal to 0.45 . That is, the total costs of access to foreign markets constitute on average around the half of the total export profits. The similar result is obtained in Eaton et al. (2008), who find that the share of fixed costs in the gross profits is a little more than half. By regressing the log of $F C_{R i}$ on the $\operatorname{logs}$ of $G D P$ and $G D P$ per capita, I find that richer countries have the lower share of fixed costs of exporting in the total export profits, while countries with larger population have the higher share. Namely,

$$
\ln F C_{R i}=\underset{(0.01)}{-0.84}+\underset{(0.003)}{0.04} \ln G D P_{i}-\underset{(0.002)}{0.14} \ln \frac{G D P_{i}}{L_{i}} .
$$

In the next subsection, I estimate the model when $\delta$ is equal to zero and compare the quantitative implications of that model with those obtained above.

\subsubsection{Identical Market Access Costs: Comparison}

If $\delta$ is equal to zero, then

$$
f_{i j}=w_{i} f_{x} \text { for } i \neq j
$$

implying identical fixed costs of trade (in terms of labor) across countries. Since I fix $\delta$ at zero, the set of parameters estimated is $\left\{\gamma_{0}, \gamma_{1}, \gamma_{2}, \gamma_{3}, \gamma_{4}, \gamma_{5}, f_{x}\right\}$.

Table 4 reports the estimated values of the parameters. The explanatory power of the model falls from $81 \%$ to $73 \%$. Hence, differences in fixed costs of trade established in the model explain $8 \%$ of the variation in the bilateral trade flows. The third column of Table 3 shows the trade 
Table 3: Trade Elasticities and Zeros

\begin{tabular}{lccc}
\hline \hline Estimator: & Data (OLS) & Model (OLS, $\delta>0)$ & Model $($ OLS, $\delta=0)$ \\
Dependent variable: & $\ln T_{i}$ & $\ln T_{i}(\hat{\Theta})$ & $\ln T_{i}(\hat{\Theta})$ \\
\hline \multirow{2}{*}{ Log of GDP } & $0.85^{* *}$ & $0.69^{* *}$ & $0.76^{* *}$ \\
& $(0.03)$ & $(0.03)$ & $(0.03)$ \\
Log of GDP per capita & $0.19^{* *}$ & $0.22^{* *}$ & $0.04^{* *}$ \\
& $(0.04)$ & $(0.02)$ & $(0.02)$ \\
\hline Correctly predicted zeros: & $100 \%$ & $35 \%$ & $9 \%$ \\
Observations: & 100 & 100 & 100 \\
\hline \hline
\end{tabular}

Table 4: Parameter Estimates $(\delta=0)$

\begin{tabular}{c|c|c|c|c|c|c|c||c}
\hline \hline$\gamma_{0}$ & $\gamma_{1}$ & $\gamma_{2}$ & $\gamma_{3}$ & $\gamma_{4}$ & $\gamma_{5}$ & $f_{x}$ & $\delta$ & $R^{2}$ \\
\hline 0.04 & 0.31 & 0.75 & 0.82 & 0.72 & 1.06 & 122.7 & $\mathbf{0}$ & $73 \%$ \\
\hline \hline
\end{tabular}

elasticities generated by the model with $\delta$ equal to zero. As it can be seen from the table, the model does slightly better in predicting trade volumes of large population countries. Doubling a country population size raises trade volumes by $76 \%$ compared to an increase of $85 \%$ in the data. However, the effect of per capita income on trade volumes is significantly lower than that in the data. Conditional on the total income, doubling a country income per capita leads on average to an increase in trade volumes of $4 \%$, while the effect observed in the data is $19 \% .{ }^{27}$ Finally, the percentage of correctly predicted zeros is $9 \%$. This constitutes the mismatch of $91 \%$, which is substantially greater than the mismatch obtained in the case when fixed costs of exporting depend on a country development level.

\footnotetext{
${ }^{27}$ The positive and significant (at the $5 \%$ significance level) effect of per capita income on trade volumes in the model with $\delta=0$ is explained by some correlation between the estimated trade barriers (distance, border, etc.) and per capita income levels. That is, some small part of the effect of per capita income can be explained by the geographical location of a country, its membership in the trade unions, or its cultural characteristics such as language.
} 


\section{Eliminating Asymmetries in Trade Costs}

In this section, I use the estimated model to explore how the elimination of asymmetries in fixed costs of trade affects consumer welfare across countries. Specifically, I consider an experiment where $\delta$ falls from 0.67 (the estimated value of $\delta$ ) to zero and examine the corresponding changes in consumer welfare. Remember that setting $\delta$ to zero removes the relationship between market access costs and development levels and, therefore, leads to symmetric fixed costs of trade: $f_{i j}=w_{i} f_{x}$ for $i \neq j$. The other parameters including $Z$ are fixed at the values obtained from the benchmark estimation procedure (see Table 2).

Consumer welfare in country $i$ (denoted as $W_{i}$ ) is equal to the real wage in that country. Namely, for $i=1 . . N$

$$
W_{i} \equiv \frac{Q_{i}}{L_{i}}=\frac{w_{i}}{P_{i}}
$$

Hence, given the parameters of the model, we can solve (12) for $\left\{w_{i}, P_{i}, M_{e i}\right\}_{i=1 . . N}$ and then

using (25), find the equilibrium value of consumer welfare in country $i$. Let us denote $\frac{\triangle W_{i}}{W_{i}}$ as the percentage change in welfare in country $i$ given the changes in the parameters of the model. That is,

$$
\frac{\triangle W_{i}}{W_{i}}=\frac{W_{i}^{\text {after }}}{W_{i}^{\text {before }}}-1,
$$

where $W_{i}^{\text {before }}$ is the equilibrium value of welfare when the parameters are equal to their estimated values and $W_{i}^{a f t e r}$ is welfare when $\delta$ is equal to zero (recall that the other parameters remain unchanged).

I find that all countries gain from the elimination of asymmetries in market access costs with the average percentage change in welfare being equal to $17 \%$. The next regression illustrates how the gains depend on country characteristics. In particular, I regress $\frac{\triangle W_{i}}{W_{i}}$ on the logs of $G D P_{i}$ and $\frac{G D P_{i}}{L_{i}}$ :

$$
\frac{\triangle W_{i}}{W_{i}}=\underset{(0.01)}{0.35}-\underset{(0.005)}{0.03} \ln G D P_{i}-\underset{(0.005)}{0.05} \ln \frac{G D P_{i}}{L_{i}} .
$$

As it can be seen, doubling a country population size on average reduces the welfare gains by $3 \%$, while doubling a country per capita income (controlling for the total income of that country) reduces the gains by $5 \%$. The former effect is explained by the fact that setting $\delta$ to zero enhances trade in all countries. Since countries with larger population tend to have a lower trade to $G D P$ ratio, those countries gain less compared to small population countries. The latter effect is based on the feature of the model that fixed costs of trade depend on country 
development level: i.e., firms in less developed countries face higher market access costs. Since fixing $\delta$ at zero eliminates this relationship, the changes in welfare are more substantial for less developed countries. I also find that removing asymmetries in fixed costs of trade dramatically reduces the number of zero bilateral trade flows. In the new equilibrium (after setting $\delta$ to zero), there are only 4 export zeros in comparison with 1399 zeros when $\delta$ is equal to 0.67.

The findings above suggest that eliminating asymmetries in fixed costs of trade not only raises consumer welfare, but also reduces welfare inequality across countries (as poor countries gain relatively more). In particular, as a measure of the welfare inequality in the model, I consider the ratio of the average income of the ten richest (in real terms) countries to that of the ten poorest countries. I find that setting $\delta$ to zero reduces the measured welfare inequality by $28 \%$.

\section{Alternative Specifications}

In this section, I consider two alternative specifications of the model. First, I assume that fixed costs of trade depend on both exporter's and importer's development levels. Second, I examine the case when variable costs of trade depend on exporter's development level, while fixed costs of trade are identical across countries.

In the paper, fixed costs of trade depend only on characteristics of an exporting country. Meanwhile, Arkolakis (2008) emphasizes that to serve a foreign market firms may need labor services from both the source and the destination countries. Eaton et al. (2008) assume that market access costs depend only on importer characteristics. To account for the importer effect on fixed costs, I assume that

$$
f_{i j}=\frac{w_{i}}{Z_{i}^{\delta}} Z_{j}^{\alpha} f_{x} \quad \text { for } i \neq j .
$$

That is, fixed costs of exporting depend on importer's development level as well. I then estimate the model applying the same estimation procedure as before. The set of the parameters I estimate is given by $\left\{\gamma_{0}, \gamma_{1}, \gamma_{2}, \gamma_{3}, \gamma_{4}, \gamma_{5}, f_{x}, \delta, \alpha\right\}$.

The second column in Table 5 shows the estimates of the parameters (the first column reports the estimates obtained in the benchmark case). As it can be inferred, there is a negative correlation between the importer development level and the fixed costs of trade. The estimate of $\alpha$ is -0.09 implying that it is relatively easier to export to more developed countries. However, the impact of the importer development level on the fixed costs is substantially lower than that 
Table 5: Alternative Specifications: Parameter Estimates

\begin{tabular}{lccc}
\hline \hline Specifications: & $(1)$ & $(2)$ & $(3)$ \\
\hline$\gamma_{0}$ & 0.49 & 0.52 & 0.28 \\
$\gamma_{1}$ & 0.14 & 0.14 & 0.16 \\
$\gamma_{2}$ & 0.76 & 0.77 & 0.72 \\
$\gamma_{3}$ & 0.97 & 0.97 & 0.99 \\
$\gamma_{4}$ & 0.78 & 0.78 & 0.72 \\
$\gamma_{5}$ & 0.94 & 0.94 & 0.94 \\
$f_{x}$ & 2.15 & 1.67 & 15.88 \\
$\delta$ & $\mathbf{0 . 6 7}$ & $\mathbf{0 . 6 2}$ & - \\
$\alpha$ & - & $-\mathbf{0 . 0 9}$ & - \\
$\beta$ & - & - & $\mathbf{0 . 2 2}$ \\
\hline$R^{2}$ & $81 \%$ & $81 \%$ & $79 \%$ \\
\hline \hline
\end{tabular}

of the exporter development level. The presence of the importer effect does not considerably affect the estimates of the other parameters and does not improve the explanatory power of the model. This suggests that the importer effect does not contribute a lot in explaining the bilateral trade flows. The third column in Table 6 reports the trade elasticities and the percentage of zeros correctly predicted by the model. As it can be seen, the presence of the importer effect does not significantly change the trade elasticities and slightly improves the ability of the model to match zeros in the data.

In his paper, Waugh (2009) assumes that variable trade costs are a function of symmetric relationships and an exporter fixed effect. He finds a negative correlation between exporter per capita income and the fixed effect, implying that poor countries face higher variable trade costs than rich countries. Following Waugh (2009), I examine a variation of the model when fixed costs of trade are identical across countries, while variable trade costs depend on the exporter development level. That is, for $i \neq j$

$$
\begin{aligned}
f_{i j} & =w_{i} f_{x} \text { and } \\
\tau_{i j} & =1+\frac{\gamma_{0}}{Z_{i}^{\beta}} D_{i j}^{\gamma_{1}} \gamma_{2}^{B_{i j}} \gamma_{3}^{L N G_{i j}} \gamma_{4}^{N A F_{i j}} \gamma_{5}^{E U_{i j}} .
\end{aligned}
$$

Hence, if $\beta$ is greater than zero, then other things equal, more developed countries tend to have 
Table 6: Alternative Specifications: Trade Elasticities and Zeros

\begin{tabular}{lcccc}
\hline \hline & Data & $(1)$ & $(2)$ & $(3)$ \\
Dependent variable: & $\ln T_{i}$ & $\ln T_{i}(\hat{\Theta})$ & $\ln T_{i}(\hat{\Theta})$ & $\ln T_{i}(\hat{\Theta})$ \\
\hline Log of GDP & $0.85^{* *}$ & $0.69^{* *}$ & $0.69^{* *}$ & $0.68^{* *}$ \\
& $(0.03)$ & $(0.03)$ & $(0.03)$ & $(0.03)$ \\
Log of GDP per capita & $0.19^{* *}$ & $0.22^{* *}$ & $0.24^{* *}$ & $0.49^{* *}$ \\
& $(0.04)$ & $(0.02)$ & $(0.03)$ & $(0.03)$ \\
\hline Correctly predicted zeros: & $100 \%$ & $35 \%$ & $36 \%$ & $27 \%$ \\
Observations: & 100 & 100 & 100 & 100 \\
\hline \hline
\end{tabular}

lower variable costs of trade. I then estimate the parameters $\left\{\gamma_{0}, \gamma_{1}, \gamma_{2}, \gamma_{3}, \gamma_{4}, \gamma_{5}, f_{x}, \beta\right\}$.

The third column in Table 5 reports the parameter estimates. The estimate of $\beta$ is 0.22 meaning a strong negative correlation between variable costs of trade and country development levels, which is consistent with the findings in Waugh (2009). The explanatory power slightly falls from $81 \%$ to $79 \%$. However, this variation of the model considerably overestimates the impact of per capita income on trade volumes (see the fourth column in Table 6). The model predicts that controlling for the total income, doubling a country income per increases trade volumes of that country by $49 \%$ (compared to $19 \%$ in the data). Moreover, the percentage of correctly predicted zeros falls from $35 \%$ to $27 \%$ constituting larger mismatch between zeros predicted by the model and those in the data.

Hence, while the relationship between variable costs of trade and development levels can also account for greater trade volumes of richer countries and zero trade flows in the data, the model in this case performs much worse in matching the trade elasticities and zeros in the data.

\section{Concluding Remarks}

This paper contributes to a rapidly growing literature analyzing the role of fixed costs of trade in explaining trade volumes. I show that an association between fixed costs of trade and countries' development levels can qualitatively and quantitatively account for the relationship between per capita income and trade volumes observed in the data and explain a number of zeros in bilateral trade flows. 
There are several directions in which further research can be pursued. First, in the paper, the association between market access costs and development levels is estimated to match the data on aggregate trade volumes. It might seem desirable, however, to estimate this association using micro-level ("independent") data and then to examine how much of the relationship between per capita income and trade volumes is explained by the variation in fixed costs of trade. Secondly, it might be interesting to incorporate nonhomothetic preferences in the model. This would enable us to capture the effects of both consumer preferences and market access costs on trade volumes in a general equilibrium framework. Finally, in the paper, I consider an environment where countries trade only in a differentiated good. This framework is more applicable to the case of trade among rich countries. In particular, the setup of the model assumes away the possibility that trade flows can be generated by differences in factor endowments. To explain better trade between countries with different factor endowments, we can extend the model by incorporating the Heckscher-Ohlin trade theory (see for example Bernard et al. (2007)). This would allow us to analyze both intra-industry and inter-industry trade and, thereby, to improve the fit of the model. I leave all the issues discussed above for future work. 


\section{References}

Arkolakis, C. (2008), "Market Penetration Costs and the New Consumers Margin in International Trade," NBER WP 14214.

Bernard, A. B., Eaton, J., Jensen, J. B. and Kortum, S. (2003), "Plants and Productivity in International Trade," American Economic Review, 93(4), 1268-1290.

Bernard, A. B., Redding, S. and Schott, P. K. (2007), "Comparative Advantage and Heterogeneous Firms," Review of Economic Studies, 74(1), 31-66.

Broda, C. and Weinstein, D. E. (2006), "Globalization and the Gains from Variety," Quarterly Journal of Economics, 121(2), 541-585.

Centre d'Etudes Prospectives et d'Informations Internationales, CEPII (2005), The CEPII Databases-Distances, http://www.cepii.fr/anglaisgraph/bdd/distances.htm

Chaney, T. (2008), "Distorted gravity: the Intensive and Extensive Margins of International Trade," American Economic Review, 98(4), 1707-1721.

Chen, M., Otsuki, T. and Wilson, J. (2006), "Do Standards Matter for Export Success?" World Bank Policy Research Working Papers. No. 3809.

Doing Business (2006), "Doing Business 2006," The World Bank Group, http://www.doingbusiness.org

Eaton, J. and Kortum, S. (2002), "Technology, Geography, and Trade." Econometrica, 70(5), 1741-79.

Eaton, J., Kortum, S. and Kramarz F. (2008), "An Anatomy of International Trade: Evidence from French Firms," University of Minnesota, mimeograph.

Feenstra, R., Lipsey, R. E., Deng, H., Ma, A. C. and Mo, H. (2005), "World Trade Flows: 1962-2000," NBER Working Paper, No. 11040.

Fieler, A. C. (2009), "Non-Homotheticity and Bilateral Trade: Evidence and a Quantitative Explanation," working paper.

Flam, H. and Helpman, E. (1987), "Vertical Product Differentiation and North-South Trade," American Economic Review, 77, 810-822. 
Ghironi, F. and Melitz, M. (2005), "International Trade and Macroeconomic Dynamics with Heterogeneous Firms," Quarterly Journal of Economics, 120(3), 865-915.

Helpman, E., Melitz, M. and Rubinstein, Y. (2008), "Estimating Trade Flows: Trading Partners and Trading Volumes," Quarterly Journal of Economics, 123(2), 441-487.

Hummels, D. and Klenow, P. J. (2002), "The Variety and Quality of a Nation's Trade," NBER WP 8712.

Hunter, L. C. (1991), "The Contribution of Nonhomothetic Preferences to Trade," Journal of International Economics, 30, 345-58.

Johnson, R. C. (2007), "Trade and Prices with Heterogeneous Firms," UC Berkeley, mimeograph.

Markusen, J. (1986), "Explaining the Volume of Trade: An Eclectic Approach," American Economic Review, 76, 1002-1011.

Matsuyama, K. (2000), "A Ricardian Model with a Continuum of Goods under Nonhomothetic Preferences: Demand Complementarities, Income Distribution, and North-South Trade," Journal of Political Economy, 108, 1093-1120.

Melitz, M. (2003), "The impact of trade on intraindustry reallocations and aggregate industry productivity," Econometrica, 71(6), 1695-1725.

Mersha, T. (1997), "TQM Implementation in LDCs: Driving and Restraining Forces," International Journal of Operations and Production Management, 17(2), 164-183.

Mitra, D. and Trindade, V. (2005), "Inequality and Trade," Canadian Journal of Economics, $38,1253-1271$.

Nordas, H., Pinali, E. and Gross, MG. (2006), "Logistics and Time as a Trade Barrier," OECD Trade Policy Working Papers, No 35.

Potoski, M. and Prakash, A. (2009), "Information Asymmetries as Trade Barriers: ISO 9000 Increases International Commerce," Journal of Policy Analysis and Management, 28(2), 221-238. Stokey, N. (1991), "The Volume and Composition of Trade between Rich and Poor Countries," Review of Economic Studies, 58, 63-80. 
United Nation Statistics Division (2007), "Industrial Statistics Database," 2007, http://comtrade.un.org/db/default.aspx

Waugh, M. (2009), "International Trade and Income Differences," University of Iowa, mimeograph.

World Bank (2007), "World Development Indicators," 2007. 


\section{Appendix A: Per Capita Income and Trade Volumes}

In this section, I prove Proposition 1. The outline of the proof is as follows (see the details of the proof in the subsections). Suppose that country 2 trades more in the equilibrium. Since trade is balanced, country 2 imports more than country 1. That is,

$$
\sum_{j>2}^{N} X_{j 2} \geq \sum_{j>2}^{N} X_{j 1}
$$

As total incomes in the countries are the same $\left(w_{1} L_{1}=w_{2} L_{2}\right),(27)$ immediately implies that the price index in country 2 is higher than that in country 1: $P_{2} \geq P_{1}$. Next, I show that if $P_{2} \geq P_{1}$ and the assumptions of the proposition hold, then country 1 exports more than country

2. This constitutes a contradiction, implying that country 1 trades strictly more than country 2 in the equilibrium. This stage of the proof has two steps.

Step 1: The free entry condition in (12) states that

$$
f_{e i}=\sum_{j=1}^{N} \operatorname{Pr}\left(\theta \geq \theta_{i j}\right) E\left(\left(\pi_{i j}(\theta)-f_{i j}\right) \mid \theta \geq \theta_{i j}\right) .
$$

Using the expression for $\pi_{i j}(\theta)$ in $(6)$ and dividing $\pi_{i j}(\theta)$ by $\pi_{i j}\left(\theta_{i j}\right)$, we obtain that

$$
\begin{aligned}
\frac{\pi_{i j}(\theta)}{\pi_{i j}\left(\theta_{i j}\right)} & =\left(\frac{\theta}{\theta_{i j}}\right)^{\sigma-1} \Longleftrightarrow \\
\pi_{i j}(\theta) & =\pi_{i j}\left(\theta_{i j}\right)\left(\frac{\theta}{\theta_{i j}}\right)^{\sigma-1} .
\end{aligned}
$$

Taking into account that $\pi_{i j}\left(\theta_{i j}\right)=f_{i j}$, the free entry condition for country $i$ can be rewritten as follows:

$$
\sum_{j=1}^{N} \frac{f_{i j}}{f_{e i}} \int_{\theta_{i j}}^{\theta_{H}}\left(\left(\frac{\theta}{\theta_{i j}}\right)^{\sigma-1}-1\right) d G(\theta)=1 .
$$

Hence, condition (28) implies that for countries 1 and 2 (recall that countries 1 and 2 do not trade with each other):

$$
\sum_{j: j \neq 2}^{N} \frac{f_{1 j}}{f_{e 1}} \int_{\theta_{1 j}}^{\theta_{H}}\left(\left(\frac{\theta}{\theta_{1 j}}\right)^{\sigma-1}-1\right) d G(\theta)=\sum_{j: j \neq 1}^{N} \frac{f_{2 j}}{f_{e 2}} \int_{\theta_{2 j}}^{\theta_{H}}\left(\left(\frac{\theta}{\theta_{2 j}}\right)^{\sigma-1}-1\right) d G(\theta) .
$$

Note that $\frac{f_{1 j}}{f_{e 1}}$ is strictly less than or equal to $\frac{f_{2 j}}{f_{e 2}}$ for all $j=1 . . N$. This implies that at least for some $j$,

$$
\int_{\theta_{1 j}}^{\theta_{H}}\left(\left(\frac{\theta}{\theta_{1 j}}\right)^{\sigma-1}-1\right) d G(\theta)>\int_{\theta_{2 j}}^{\theta_{H}}\left(\left(\frac{\theta}{\theta_{2 j}}\right)^{\sigma-1}-1\right) d G(\theta) .
$$


Otherwise, (29) does not hold. This implies that $\theta_{1 j}<\theta_{2 j}$ for some $j$. I show that in fact, $\theta_{1 j}<\theta_{2 j}$ for all $j>2$ (see details in the next subsection). That is, country 1 has a higher fraction of firms in the total mass of entrants exporting to country $j$ for any $j>2$.

Step 2: Next, I show that country 1 has higher exports to domestic sales ratio than country 2. This means that country 1 exports more than country 2 , as total incomes of the countries are the same. In the next subsection, I show that the result of the previous step and the fact that $\frac{f_{1 j}}{f_{11}}$ is strictly less than $\frac{f_{2 j}}{f_{22}}$ for all $j>2$ imply that

$$
\frac{\int_{\theta_{1 j}}^{\theta_{H}} \theta^{\sigma-1} d G(\theta)}{\int_{\theta_{11}}^{\theta_{H}} \theta^{\sigma-1} d G(\theta)}>\frac{\int_{\theta_{2 j}}^{\theta_{H}} \theta^{\sigma-1} d G(\theta)}{\int_{\theta_{22}}^{\theta_{H}} \theta^{\sigma-1} d G(\theta)} \text { for all } j>2 .
$$

As we assume that $\tau_{1 j}=\tau_{2 j}$ for all $j>2,(30)$ implies that

$$
\frac{\sum_{j>2}^{N}\left(\frac{1}{\tau_{1 j}}\right)^{\sigma-1} \frac{w_{j} L_{j}}{P_{j}^{1-\sigma} \int_{\theta_{1 j}}^{\theta_{H}} \theta^{\sigma-1} d G(\theta)}}{\int_{\theta_{11}}^{\theta_{H}} \theta^{\sigma-1} d G(\theta)}>\frac{\sum_{j>2}^{N}\left(\frac{1}{\tau_{2 j}}\right)^{\sigma-1} \frac{w_{j} L_{j}}{P_{j}^{1-\sigma}} \int_{\theta_{2 j}}^{\theta_{H}} \theta^{\sigma-1} d G(\theta)}{\int_{\theta_{22}}^{\theta_{H}} \theta^{\sigma-1} d G(\theta)} .
$$

Note that $P_{2} \geq P_{1}$ implies that $\frac{w_{1} L_{1}}{P_{1}^{1-\sigma}} \leq \frac{w_{2} L_{2}}{P_{2}^{1-\sigma}}$. This in turn means that

$$
\frac{\sum_{j>2}^{N}\left(\frac{1}{\tau_{1 j}}\right)^{\sigma-1} \frac{w_{j} L_{j}}{P_{j}^{1-\sigma}} \int_{\theta_{1 j}}^{\theta_{H}} \theta^{\sigma-1} d G(\theta)}{\frac{w_{1} L_{1}}{P_{1}^{1-\sigma}} \int_{\theta_{11}}^{\theta_{H}} \theta^{\sigma-1} d G(\theta)}>\frac{\sum_{j>2}^{N}\left(\frac{1}{\tau_{2 j}}\right)^{\sigma-1} \frac{w_{j} L_{j}}{P_{j}^{1-\sigma}} \int_{\theta_{2 j}}^{\theta_{H}} \theta^{\sigma-1} d G(\theta)}{\frac{w_{2} L_{2}}{P_{2}^{1-\sigma}} \int_{\theta_{22}}^{\theta_{H}} \theta^{\sigma-1} d G(\theta)},
$$

which is equivalent to

$$
\frac{\sum_{j>2}^{N} X_{1 j}}{X_{11}}>\frac{\sum_{j>2}^{N} X_{2 j}}{X_{22}}
$$

This finishes the proof. In the next sections, I provide the details of the proof.

\section{Proof of Step 1}

At this stage of the proof, I show that $\theta_{1 j}<\theta_{2 j}$ for all $j>2$. Specifically, I first show that if $\theta_{1 j^{*}}<\theta_{2 j^{*}}$ for some $j^{*}>2$, then $\theta_{1 j}<\theta_{2 j}$ for all $j>2$. Then, I prove that the equality (29) implies that $\theta_{1 j}<\theta_{2 j}$ at least for some $j>2$. This finishes the proof.

From the zero profit condition (7),

$$
\theta_{i j}=\frac{w_{i}}{Z_{i}} \tau_{i j}\left(\frac{1}{C} \frac{P_{j}^{1-\sigma}}{w_{j} L_{j}}\right)^{\frac{1}{\sigma-1}} f_{i j}^{\frac{1}{\sigma-1}}
$$


Substituting for $f_{i j}$, the cutoffs are given by

$$
\begin{aligned}
\theta_{11} & =\frac{w_{1}}{Z_{1}}\left(w_{1} f_{d}\right)^{\frac{1}{\sigma-1}}\left(\frac{1}{C} \frac{P_{1}^{1-\sigma}}{w_{1} L_{1}}\right)^{\frac{1}{\sigma-1}}, \\
\theta_{22} & =\frac{w_{2}}{Z_{2}}\left(w_{2} f_{d}\right)^{\frac{1}{\sigma-1}}\left(\frac{1}{C} \frac{P_{2}^{1-\sigma}}{w_{2} L_{2}}\right)^{\frac{1}{\sigma-1}}, \\
\theta_{i j} & =\frac{w_{i}}{Z_{i}}\left(w_{i} f_{d}\right)^{\frac{1}{\sigma-1}}\left(1+\frac{f_{x}}{f_{d} Z_{i}^{\delta}}\right)^{\frac{1}{\sigma-1}} \tau_{i j}\left(\frac{1}{C} \frac{P_{j}^{1-\sigma}}{w_{j} L_{j}}\right)^{\frac{1}{\sigma-1}} \text { for } j>2 \text { and } i=1,2 .
\end{aligned}
$$

Given the expressions for the cutoffs, it is straightforward to show that if $\theta_{1 j^{*}}<\theta_{2 j^{*}}$ for some $j^{*}>2$, then

$$
\begin{aligned}
& \frac{w_{1}}{Z_{1}}\left(w_{1} f_{d}\right)^{\frac{1}{\sigma-1}}\left(1+\frac{f_{x}}{f_{d} Z_{1}^{\delta}}\right)^{\frac{1}{\sigma-1}} \tau_{1 j}\left(\frac{1}{C} \frac{P_{j}^{1-\sigma}}{w_{j} L_{j}}\right)^{\frac{1}{\sigma-1}} \\
< & \frac{w_{2}}{Z_{2}}\left(w_{2} f_{d}\right)^{\frac{1}{\sigma-1}}\left(1+\frac{f_{x}}{f_{d} Z_{2}^{\delta}}\right)^{\frac{1}{\sigma-1}} \tau_{2 j}\left(\frac{1}{C} \frac{P_{j}^{1-\sigma}}{w_{j} L_{j}}\right)^{\frac{1}{\sigma-1}} .
\end{aligned}
$$

As we assume that $\tau_{1 j}=\tau_{2 j}$ for all $j>2$, the last inequality implies that

$$
\frac{w_{1}}{Z_{1}}\left(w_{1} f_{d}\right)^{\frac{1}{\sigma-1}}\left(1+\frac{f_{x}}{f_{d} Z_{1}^{\delta}}\right)^{\frac{1}{\sigma-1}}<\frac{w_{2}}{Z_{2}}\left(w_{2} f_{d}\right)^{\frac{1}{\sigma-1}}\left(1+\frac{f_{x}}{f_{d} Z_{2}^{\delta}}\right)^{\frac{1}{\sigma-1}} .
$$

This in turn means that $\theta_{1 j}<\theta_{2 j}$ for all $j>2$.

To reduce the notation in this subsection, I denote $\int_{\theta_{i j}}^{\theta_{H}}\left(\left(\frac{\theta}{\theta_{i j}}\right)^{\sigma-1}-1\right) d G(\theta)$ as $H\left(\theta_{i j}\right)$. Notice that $H^{\prime}\left(\theta_{i j}\right)<0$. Given the new notation, the equality (29) can be rewritten as follows (recall that country 1 and 2 do not trade with each other):

$$
\sum_{j>2}^{N} \frac{f_{1 j}}{f_{e 1}} H\left(\theta_{1 j}\right)+\frac{f_{11}}{f_{e 1}} H\left(\theta_{11}\right)=\sum_{j>2}^{N} \frac{f_{2 j}}{f_{e 2}} H\left(\theta_{2 j}\right)+\frac{f_{22}}{f_{e 2}} H\left(\theta_{22}\right) .
$$

Substituting for $f_{e 1}, f_{e 2}, f_{1 j}, f_{2 j}, f_{11}$, and $f_{22}$ (see (11) and (10)), we have

$$
\left(\frac{f_{d}}{f_{e}}+\frac{f_{x}}{Z_{1}^{\delta}}\right) \sum_{j>2}^{N} H\left(\theta_{1 j}\right)+\frac{f_{d}}{f_{e}} H\left(\theta_{11}\right)=\left(\frac{f_{d}}{f_{e}}+\frac{f_{x}}{Z_{2}^{\delta}}\right) \sum_{j>2}^{N} H\left(\theta_{2 j}\right)+\frac{f_{d}}{f_{e}} H\left(\theta_{22}\right) .
$$

To finish the proof, I consider $\frac{w_{1}}{Z_{1}} w_{1}^{\frac{1}{\sigma-1}}$ and $\frac{w_{2}}{Z_{2}} w_{2}^{\frac{1}{\sigma-1}}$. In general, we do not know whether $\frac{w_{1}}{Z_{1}} w_{1}^{\frac{1}{\sigma-1}}$ is greater or less than $\frac{w_{2}}{Z_{2}} w_{2}^{\frac{1}{\sigma-1}}$ in the equilibrium. Therefore, we need to examine two cases. First, if $\frac{w_{1}}{Z_{1}} w_{1}^{\frac{1}{\sigma-1}}<\frac{w_{2}}{Z_{2}} w_{2}^{\frac{1}{\sigma-1}}$, then $\left(\right.$ as $Z_{1}>Z_{2}$ ),

$$
\frac{w_{1}}{Z_{1}}\left(w_{1} f_{d}\right)^{\frac{1}{\sigma-1}}\left(1+\frac{f_{x}}{f_{d} Z_{1}^{\delta}}\right)^{\frac{1}{\sigma-1}}<\frac{w_{2}}{Z_{2}}\left(w_{2} f_{d}\right)^{\frac{1}{\sigma-1}}\left(1+\frac{f_{x}}{f_{d} Z_{2}^{\delta}}\right)^{\frac{1}{\sigma-1}}
$$


From (33) and the fact that $\tau_{1 j}=\tau_{2 j}$, the last inequality results in that $\theta_{1 j}<\theta_{2 j}$ for all $j>2$. Second, if $\frac{w_{1}}{Z_{1}} w_{1}^{\frac{1}{\sigma-1}} \geq \frac{w_{2}}{Z_{2}} w_{2}^{\frac{1}{\sigma-1}}$, then (remember that $w_{1} L_{1}=w_{2} L_{2}, P_{2} \geq P_{1}$, and $\sigma>1$ )

$$
\theta_{11}=\frac{w_{1}}{Z_{1}}\left(w_{1} f_{d}\right)^{\frac{1}{\sigma-1}}\left(\frac{1}{C} \frac{P_{1}^{1-\sigma}}{w_{1} L_{1}}\right)^{\frac{1}{\sigma-1}} \geq \frac{w_{2}}{Z_{2}}\left(w_{2} f_{d}\right)^{\frac{1}{\sigma-1}}\left(\frac{1}{C} \frac{P_{2}^{1-\sigma}}{w_{2} L_{2}}\right)^{\frac{1}{\sigma-1}}=\theta_{22}
$$

Since $H^{\prime}(\cdot)<0$, we obtain that

$$
\frac{f_{d}}{f_{e}} H\left(\theta_{11}\right) \leq \frac{f_{d}}{f_{e}} H\left(\theta_{22}\right)
$$

This means that in order for (34) holds, $\theta_{1 j}$ should be strictly less than $\theta_{2 j}$ for some $j>2$, implying that $\theta_{1 j}<\theta_{2 j}$ for all $j>2$ (see the considerations before).

\section{Proof of Step 2}

Here I show that in the equilibrium,

$$
\frac{\int_{\theta_{1 j}}^{\theta_{H}} \theta^{\sigma-1} d G(\theta)}{\int_{\theta_{11}}^{\theta_{H}} \theta^{\sigma-1} d G(\theta)}>\frac{\int_{\theta_{2 j}}^{\theta_{H}} \theta^{\sigma-1} d G(\theta)}{\int_{\theta_{22}}^{\theta_{H}} \theta^{\sigma-1} d G(\theta)} \text { for all } j>2 .
$$

To prove this result, I need the following technical lemma.

Lemma 1 For any positive numbers $A$ and $B$ such that $A \geq B$, a function $J(x)=\frac{\int_{A x}^{\theta_{H}} \theta^{\sigma-1} d G(\theta)}{\int_{B x}^{\theta_{H}} \theta^{\sigma-1} d G(\theta)}$ is weakly decreasing in $x$.

Proof. The proof directly follows from differentiating $J(x)$. Namely, $J^{\prime}(x) \leq 0$ if and only if $\frac{x^{\sigma} g(x)}{\int_{x}^{\theta} H t^{\sigma-1} d G(t)}$ is weakly increasing in $x$, which is assumed in the condition of the proposition.

Next, I use this lemma to show that (35) holds. To do so, we need to construct several additional variables. Specifically, we define

$$
\begin{aligned}
& x_{1}=\frac{w_{1}}{Z_{1}}\left(w_{1} f_{d}\right)^{\frac{1}{\sigma-1}}\left(1+\frac{f_{x}}{f_{d} Z_{1}^{\delta}}\right)^{\frac{1}{\sigma-1}} \text { and } \\
& x_{2}=\frac{w_{2}}{Z_{2}}\left(w_{2} f_{d}\right)^{\frac{1}{\sigma-1}}\left(1+\frac{f_{x}}{f_{d} Z_{2}^{\delta}}\right)^{\frac{1}{\sigma-1}} .
\end{aligned}
$$

Note that the proof of Step 1 implies that $x_{1}<x_{2}$ in the equilibrium (as $\theta_{1 j}<\theta_{2 j}$ for all $j>2$ ).

In addition, for arbitrary $j>2$ we define $A=\tau_{1 j}\left(\frac{1}{C} \frac{P_{j}^{1-\sigma}}{w_{j} L_{j}}\right)^{\frac{1}{\sigma-1}}$ and $B=\frac{\left(\frac{1}{C} \frac{P_{1}^{1-\sigma}}{w_{1} L_{1}}\right)^{\frac{1}{\sigma-1}}}{\left(1+\frac{f_{x}}{f_{d} Z_{1}^{\delta}}\right)^{\frac{1}{\sigma-1}}}$. Recall 
that Assumption 2 says that $\theta_{1 j} \geq \theta_{11}$ for all $j>2$. From (31) and (33), $\theta_{1 j} \geq \theta_{11}$ is equivalent to

$$
\begin{aligned}
\frac{w_{1}}{Z_{1}}\left(w_{1} f_{d}\right)^{\frac{1}{\sigma-1}}\left(1+\frac{f_{x}}{f_{d} Z_{1}^{\delta}}\right)^{\frac{1}{\sigma-1}} \tau_{1 j}\left(\frac{1}{C} \frac{P_{j}^{1-\sigma}}{w_{j} L_{j}}\right)^{\frac{1}{\sigma-1}} \geq \frac{w_{1}}{Z_{1}}\left(w_{1} f_{d}\right)^{\frac{1}{\sigma-1}}\left(\frac{1}{C} \frac{P_{1}^{1-\sigma}}{w_{1} L_{1}}\right)^{\frac{1}{\sigma-1}} \Longleftrightarrow \\
\tau_{1 j}\left(\frac{1}{C} \frac{P_{j}^{1-\sigma}}{w_{j} L_{j}}\right)^{\frac{1}{\sigma-1}} \geq \frac{\left(\frac{1}{C} \frac{P_{1}^{1-\sigma}}{w_{1} L_{1}}\right)^{\frac{1}{\sigma-1}}}{\left(1+\frac{f_{x}}{f_{d} Z_{1}^{\delta}}\right)^{\frac{1}{\sigma-1}}} .
\end{aligned}
$$

The last inequality implies that $A \geq B$.

Next, I apply Lemma 1 for $x_{1}, x_{2}, A$, and $B$ defined above. As $x_{1}<x_{2}$, Lemma 1 implies that $J\left(x_{1}\right) \geq J\left(x_{2}\right)$ or

$$
\frac{\int_{A x_{1}}^{\theta_{H}} \theta^{\sigma-1} d G(\theta)}{\int_{B x_{1}}^{\theta_{H}} \theta^{\sigma-1} d G(\theta)} \geq \frac{\int_{A x_{2}}^{\theta_{H}} \theta^{\sigma-1} d G(\theta)}{\int_{B x_{2}}^{\theta_{H}} \theta^{\sigma-1} d G(\theta)} .
$$

Note that from (31) and (33),

$$
\begin{aligned}
A x_{1} & =\frac{w_{1}}{Z_{1}}\left(w_{1} f_{d}\right)^{\frac{1}{\sigma-1}}\left(1+\frac{f_{x}}{f_{d} Z_{1}^{\delta}}\right)^{\frac{1}{\sigma-1}} \tau_{1 j}\left(\frac{1}{C} \frac{P_{j}^{1-\sigma}}{w_{j} L_{j}}\right)^{\frac{1}{\sigma-1}}=\theta_{1 j}, \\
B x_{1} & =\frac{\left(\frac{1}{C} \frac{P_{1}^{1-\sigma}}{w_{1} L_{1}}\right)^{\frac{1}{\sigma-1}}}{\left(1+\frac{f_{x}}{f_{d} Z_{1}^{\delta}}\right)^{\frac{1}{\sigma-1}}} \frac{w_{1}}{Z_{1}}\left(w_{1} f_{d}\right)^{\frac{1}{\sigma-1}}\left(1+\frac{f_{x}}{f_{d} Z_{1}^{\delta}}\right)^{\frac{1}{\sigma-1}}=\frac{w_{1}}{Z_{1}}\left(w_{1} f_{d}\right)^{\frac{1}{\sigma-1}}\left(\frac{1}{C} \frac{P_{1}^{1-\sigma}}{w_{1} L_{1}}\right)^{\frac{1}{\sigma-1}}=\theta_{11} .
\end{aligned}
$$

Moreover, from (33) and the assumption that $\tau_{1 j}=\tau_{2 j}$,

$$
\begin{aligned}
A x_{2} & =\tau_{1 j}\left(\frac{1}{C} \frac{P_{j}^{1-\sigma}}{w_{j} L_{j}}\right)^{\frac{1}{\sigma-1}} \frac{w_{2}}{Z_{2}}\left(w_{2} f_{d}\right)^{\frac{1}{\sigma-1}}\left(1+\frac{f_{x}}{f_{d} Z_{2}^{\delta}}\right)^{\frac{1}{\sigma-1}} \\
& =\tau_{2 j}\left(\frac{1}{C} \frac{P_{j}^{1-\sigma}}{w_{j} L_{j}}\right)^{\frac{1}{\sigma-1}} \frac{w_{2}}{Z_{2}}\left(w_{2} f_{d}\right)^{\frac{1}{\sigma-1}}\left(1+\frac{f_{x}}{f_{d} Z_{2}^{\delta}}\right)^{\frac{1}{\sigma-1}} \\
& =\theta_{2 j} .
\end{aligned}
$$

Summarizing the findings above, we can rewrite (36) as follows:

$$
\begin{aligned}
& \frac{\int_{A x_{1}}^{\theta_{H}} \theta^{\sigma-1} d G(\theta)}{\int_{B x_{1}}^{\theta_{H}} \theta^{\sigma-1} d G(\theta)} \geq \frac{\int_{A x_{2}}^{\theta_{H}} \theta^{\sigma-1} d G(\theta)}{\int_{B x_{2}}^{\theta_{H}} \theta^{\sigma-1} d G(\theta)} \Longleftrightarrow \\
& \frac{\int_{\theta_{1 j}}^{\theta_{H}} \theta^{\sigma-1} d G(\theta)}{\int_{\theta_{11}}^{\theta_{H}} \theta^{\sigma-1} d G(\theta)} \geq \frac{\int_{\theta_{2 j}}^{\theta_{H}} \theta^{\sigma-1} d G(\theta)}{\int_{B x_{2}}^{\theta_{H}} \theta^{\sigma-1} d G(\theta)} .
\end{aligned}
$$

Finally, since $\frac{P_{1}^{1-\sigma}}{w_{1} L_{1}} \geq \frac{P_{2}^{1-\sigma}}{w_{2} L_{2}}$ and $1+\frac{f_{x}}{f_{d} Z_{1}^{\delta}}<1+\frac{f_{x}}{f_{d} Z_{2}^{\delta}}$ (this is implied by $P_{2} \geq P_{1}$ and $Z_{1}>Z_{2}$ ),

$$
B x_{2}=\frac{\left(\frac{1}{C} \frac{P_{1}^{1-\sigma}}{w_{1} L_{1}}\right)^{\frac{1}{\sigma-1}}}{\left(1+\frac{f_{x}}{f_{d} Z_{1}^{\delta}}\right)^{\frac{1}{\sigma-1}}} x_{2}>\frac{\left(\frac{1}{C} \frac{P_{2}^{1-\sigma}}{w_{2} L_{2}}\right)^{\frac{1}{\sigma-1}}}{\left(1+\frac{f_{x}}{f_{d} Z_{2}^{\delta}}\right)^{\frac{1}{\sigma-1}}} x_{2} .
$$


From (32),

$$
\begin{aligned}
\frac{\left(\frac{1}{C} \frac{P_{2}^{1-\sigma}}{w_{2} L_{2}}\right)^{\frac{1}{\sigma-1}}}{\left(1+\frac{f_{x}}{f_{d} Z_{2}^{\delta}}\right)^{\frac{1}{\sigma-1}}} x_{2} & =\frac{\left(\frac{1}{C} \frac{P_{2}^{1-\sigma}}{w_{2} L_{2}}\right)^{\frac{1}{\sigma-1}}}{\left(1+\frac{f_{x}}{f_{d} Z_{2}^{\delta}}\right)^{\frac{1}{\sigma-1}}} \frac{w_{2}}{Z_{2}}\left(w_{2} f_{d}\right)^{\frac{1}{\sigma-1}}\left(1+\frac{f_{x}}{f_{d} Z_{2}^{\delta}}\right)^{\frac{1}{\sigma-1}} \\
& =\theta_{22} .
\end{aligned}
$$

That is,

$$
B x_{2}>\theta_{22}
$$

The last inequality and (37) immediately imply that

$$
\frac{\int_{\theta_{1 j}}^{\theta_{H}} \theta^{\sigma-1} d G(\theta)}{\int_{\theta_{11}}^{\theta_{H}} \theta^{\sigma-1} d G(\theta)}>\frac{\int_{\theta_{2 j}}^{\theta_{H}} \theta^{\sigma-1} d G(\theta)}{\int_{\theta_{22}}^{\theta_{H}} \theta^{\sigma-1} d G(\theta)} .
$$

Since the choice of $j$ was arbitrary, the last inequality holds for all $j>2$.

\section{Appendix B: Robustness Checks}

In this part of the Appendix, I check the robustness of the quantitative implications of the model to changes in the values of the unidentifiable parameters. Namely, I reestimate the model fixing the parameters $\{\sigma, k\}$ at different values. I do not report the effects of changes in $\left\{\theta_{L}, \theta_{H}, f_{e}, f_{d}\right\}$, as they do not entirely affect the explanatory power and quantitative implications of the model (the generated trade elasticities and "true" zeros are the same as those predicted by the main model).

I consider one by one changes in $\{\sigma, k\}$. That is, I change the value of one parameter fixing the others at the values set in the main body of the paper. In particular, I examine the following changes: $\sigma$ falls from 3.8 to 3 and $k$ rises from 3.4 to 4 . Table 7 reports the parameter estimates. As it can be seen, the changes in $\{\sigma, k\}$ lead to the different estimates of the parameters. However, the explanatory power remains the same. Table 8 shows the trade elasticities and the percentage of "true" zeros predicted by the model. Given the new values of $\{\sigma, k\}$, the model predicts the same effect of population size on trade volumes as the main model does, but somewhat amplifies the impact of per capita income. Doubling a country income per capita (keeping the total income unaltered) leads to an increase in trade volumes of $31 \%(\sigma=3)$ and of $27 \%(k=4)$, while the main model predicts a rise in trade volumes of $22 \%$. 
Table 7: Robustness Checks: Parameter Estimates

\begin{tabular}{lc|cc}
\hline \hline & Main Model & Model: $k=4$ & Model: $\sigma=3$ \\
\hline$\gamma_{0}$ & 0.49 & 0.20 & 0.40 \\
$\gamma_{1}$ & 0.14 & 0.18 & 0.15 \\
$\gamma_{2}$ & 0.76 & 0.67 & 0.69 \\
$\gamma_{3}$ & 0.97 & 0.95 & 0.96 \\
$\gamma_{4}$ & 0.78 & 0.69 & 0.67 \\
$\gamma_{5}$ & 0.94 & 0.90 & 0.85 \\
$f_{x}$ & 2.15 & 9.67 & 2.38 \\
$\delta$ & 0.67 & 0.65 & 0.49 \\
\hline$R^{2}$ & $81 \%$ & $81 \%$ & $81 \%$ \\
\hline \hline
\end{tabular}

Table 8: Robustness Checks: Trade Elasticities and Zeros

\begin{tabular}{lcc|cc}
\hline \hline & Data & Main Model & Model: $\sigma=3$ & Model: $k=4$ \\
Dependent variable: & $\ln T_{i}$ & $\ln T_{i}(\hat{\Theta})$ & $\ln T_{i}(\hat{\Theta})$ & $\ln T_{i}(\hat{\Theta})$ \\
\hline \multirow{2}{*}{ Log of GDP } & $0.85^{* *}$ & $0.69^{* *}$ & $0.68^{* *}$ & $0.68^{* *}$ \\
& $(0.03)$ & $(0.03)$ & $(0.03)$ & $(0.03)$ \\
Log of GDP per capita & $0.19^{* *}$ & $0.22^{* *}$ & $0.31^{* *}$ & $0.27^{* *}$ \\
& $(0.04)$ & $(0.02)$ & $(0.03)$ & $(0.03)$ \\
\hline Correctly predicted zeros: & $100 \%$ & $35 \%$ & $34 \%$ & $35 \%$ \\
Observations: & 100 & 100 & 100 & 100 \\
\hline \hline
\end{tabular}

\section{Appendix $C$ : Alternative Restrictions}

In this section, I consider alternative restrictions in the estimation procedure. Specifically, I solve

$$
\min _{\Theta} \sum_{i, j: i \neq j}\left(X_{i j}^{o}-X_{i j}(Z(w, L, \Theta), L, \Theta)\right)^{2}
$$

subject to

$$
(1-\varepsilon) \Psi_{T}(Z(w, L, \Theta), L, \Theta)+\varepsilon \Psi_{F}(Z(w, L, \Theta), L, \Theta)=0
$$

where $\Psi_{T}(Z, L, \Theta)$ is the difference between the number of correctly predicted zeros and the number of zeros in the data and $\Psi_{F}(Z, L, \Theta)$ is the mismatch (zeros that are predicted by the 
Table 9: Alternative Restrictions: Parameter Estimates

\begin{tabular}{lccc}
\hline \hline The restriction: & $\varepsilon=0.5$ & $\varepsilon=0.25$ & $\varepsilon=0.75$ \\
\hline$\gamma_{0}$ & 0.49 & 0.40 & 0.55 \\
$\gamma_{1}$ & 0.14 & 0.14 & 0.14 \\
$\gamma_{2}$ & 0.76 & 0.72 & 0.77 \\
$\gamma_{3}$ & 0.97 & 0.97 & 0.98 \\
$\gamma_{4}$ & 0.78 & 0.78 & 0.78 \\
$\gamma_{5}$ & 0.94 & 0.95 & 0.95 \\
$f_{x}$ & 2.15 & 5.89 & 1.12 \\
$\delta$ & $\mathbf{0 . 6 7}$ & $\mathbf{0 . 6 4}$ & $\mathbf{0 . 6 4}$ \\
\hline$R^{2}$ & $81 \%$ & $80 \%$ & $81 \%$ \\
\hline \hline
\end{tabular}

model but not observed in the data). I consider two cases: $\varepsilon=0.25$ and $\varepsilon=0.75$. Recall that in the main model, $\varepsilon=0.5$. Hence, the former case implies a lower weight attached to the mismatch compared to the main model, while the latter implies a higher weight.

Table 9 reports the results. As it can be seen, the estimates of many parameters do not change compared to the main model (the only substantial changes are in the estimates of $\gamma_{0}$ and $f_{x}$ ). The explanatory power of the model does not change as well. Table 10 shows the trade elasticities and the number of zero trade flows simulated by the model for the different restrictions. As it can be inferred from the table, a lower weight attached to the mismatch leads to much more zeros predicted by the model. If $\varepsilon=0.25$, then the model predicts 2607 zeros (compared to 1404 when $\varepsilon=0.5$ ). However, many of those zeros are "false" zeros. The number of correctly predicted zeros is 796 . Therefore, lower $\varepsilon$ increases both the number of correctly predicted zeros and the mismatch. Similarly, higher $\varepsilon$ reduces both the mismatch and the number of correctly predicted zeros (see the fourth column of Table 10). Finally, the simulated trade elasticities are not much different from those obtained before.

\section{Appendix $D$ : Alternative Estimation Procedures}

Another robustness check is to apply an alternative estimation procedure. The point is that nonlinear least squares (NLLS) attach greater weights to observations with higher values. Therefore, if high value observations have larger variance, then non-linear least squares may lead to inef- 
Table 10: Alternative Restrictions: Trade Elasticities and Zeros

\begin{tabular}{lc|ccc}
\hline \hline & Data & $\varepsilon=0.5$ & $\varepsilon=0.25$ & $\varepsilon=0.75$ \\
Dependent variable: & $\ln T_{i}$ & $\ln T_{i}(\hat{\Theta})$ & $\ln T_{i}(\hat{\Theta})$ & $\ln T_{i}(\hat{\Theta})$ \\
\hline \multirow{2}{*}{ Log of GDP } & $0.85^{* *}$ & $0.69^{* *}$ & $0.68^{* *}$ & $0.70^{* *}$ \\
& $(0.03)$ & $(0.03)$ & $(0.03)$ & $(0.03)$ \\
Log of GDP per capita & $0.19^{* *}$ & $0.22^{* *}$ & $0.31^{* *}$ & $0.17^{* *}$ \\
\hline Total number of zeros: & $(0.04)$ & $(0.02)$ & $(0.03)$ & $(0.03)$ \\
Correctly predicted zeros: & 1399 & 1404 & 2607 & 604 \\
\hline \hline
\end{tabular}

ficient estimates. I examine two alternative estimation procedures: restricted non-linear least deviations (NLLD) and restricted non-linear least squares applied to logarithms rather than levels $(\mathrm{NLLS}(\log ))$. Both of these procedures attach lower weights to high value observations compared to the procedure used in the paper.

In the case of non-linear least deviations we solve the following minimization problem:

$$
\min _{\Theta} \sum_{i, j: i \neq j}\left|X_{i j}^{o}-X_{i j}(Z(w, L, \Theta), L, \Theta)\right|
$$

subject to

$$
\Psi(Z(w, L, \Theta), L, \Theta)=0
$$

While non-linear least squares applied to logarithms imply that the estimate of $\Theta$ solves

$$
\min _{\Theta} \sum_{i, j: i \neq j}\left(\log \left(X_{i j}^{o}+1\right)-\log \left(X_{i j}(Z(w, L, \Theta), L, \Theta)+1\right)\right)^{2}
$$

subject to

$$
\Psi(Z(w, L, \Theta), L, \Theta)=0
$$

Notice that we cannot directly convert to logarithms, as there are zeros in the data. Therefore, I use another monotonic transformation. Specifically, instead of $\log \left(X_{i j}^{o}\right)$ I consider $\log \left(X_{i j}^{o}+1\right)$. This solves the problem of zeros. Moreover, if $X_{i j}^{o}$ is equal to zero, then $\log \left(X_{i j}^{o}+1\right)$ is equal to zero as well.

Table 11 reports the parameter estimates obtained by applying $N L L D$ and $N L L S(\log )$ (the first column of the table shows the non-linear least squares estimates). The results of the 
Table 11: Alternative Estimation Procedures: Parameter Estimates

\begin{tabular}{lccc}
\hline \hline Estimation procedure: & NLLS & NLLD & NLLS(log) \\
\hline$\gamma_{0}$ & 0.49 & 0.60 & 0.58 \\
$\gamma_{1}$ & 0.14 & 0.17 & 0.17 \\
$\gamma_{2}$ & 0.76 & 0.73 & 0.71 \\
$\gamma_{3}$ & 0.97 & 0.86 & 0.85 \\
$\gamma_{4}$ & 0.78 & 0.63 & 0.69 \\
$\gamma_{5}$ & 0.94 & 0.82 & 0.92 \\
$f_{x}$ & 2.15 & 1.35 & 1.24 \\
$\delta$ & $\mathbf{0 . 6 7}$ & $\mathbf{0 . 6 2}$ & $\mathbf{0 . 6 6}$ \\
\hline$R^{2}$ & $81 \%$ & $44 \%$ & $81 \%$ \\
\hline \hline
\end{tabular}

Table 12: Alternative Estimation Procedures: Trade Elasticities and Zeros

\begin{tabular}{lc|ccc}
\hline \hline & Data & NLLS & NLLD & NLLS $(\log )$ \\
Dependent variable: & $\ln T_{i}$ & $\ln T_{i}(\hat{\Theta})$ & $\ln T_{i}(\hat{\Theta})$ & $\ln T_{i}(\hat{\Theta})$ \\
\hline \multirow{2}{*}{ Log of GDP } & $0.85^{* *}$ & $0.69^{* *}$ & $0.63^{* *}$ & $0.63^{* *}$ \\
& $(0.03)$ & $(0.03)$ & $(0.03)$ & $(0.03)$ \\
Log of GDP per capita & $0.19^{* *}$ & $0.22^{* *}$ & $0.33^{* *}$ & $0.30^{* *}$ \\
& $(0.04)$ & $(0.02)$ & $(0.03)$ & $(0.03)$ \\
\hline Correctly predicted zeros: & $100 \%$ & $35 \%$ & $34 \%$ & $35 \%$ \\
Observations: & 100 & 100 & 100 & 100 \\
\hline \hline
\end{tabular}

both procedures imply a negative correlation between country development levels and market access costs. Moreover, the estimates of $\delta$ are close to that obtained by applying $N L L S$. The estimates of $\delta$ vary from $0.62(N L L D)$ to $0.66(N L L S(\log ))$, while $N L L S$ result in $\delta$ equal to 0.67. The estimates of the other parameters do not vary considerably as well. Table 12 shows the comparison of the simulated trade elasticities obtained by applying different estimation procedures. As it can be inferred, the model estimated by $N L L D$ and $N L L S(\log )$ slightly reduces the effect of population size on trade volumes and amplifies the impact of per capita income compared to the model estimated by $N L L S$. Finally, all procedures result in the same percentage of correctly predicted zeros. 
Figure 1: Trade vs GDP in 1995 (the 100 largest countries in terms of GDP)

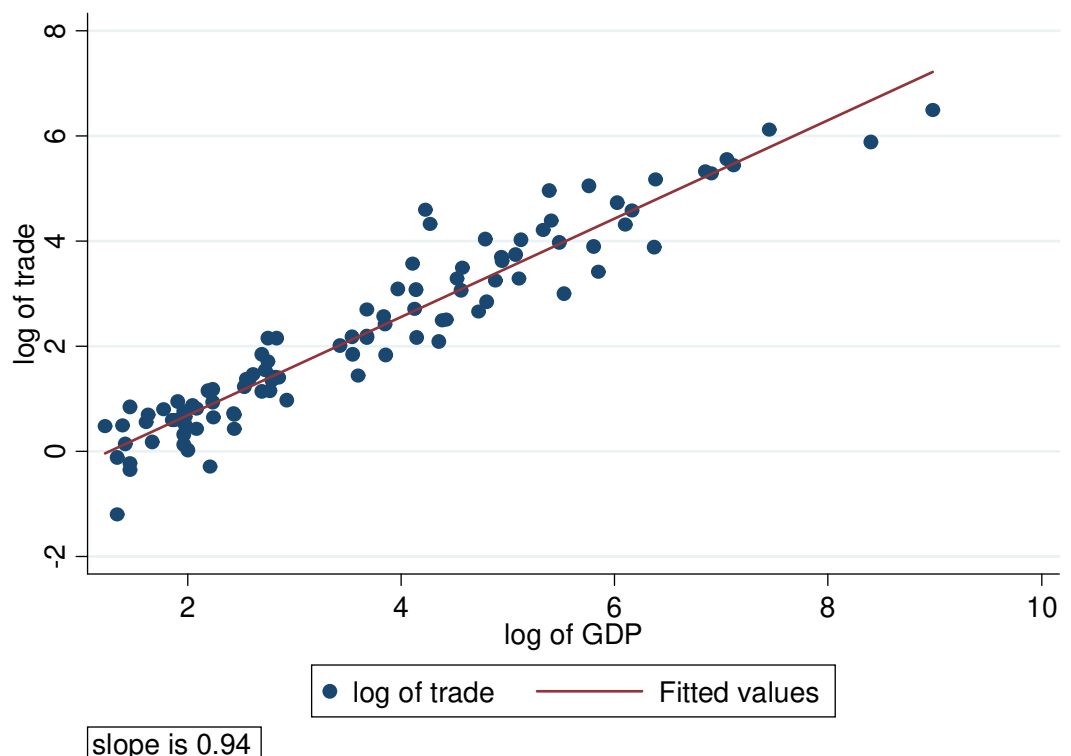

slope is 0.94 
Figure 2: Residuals vs GDP per capita and population size

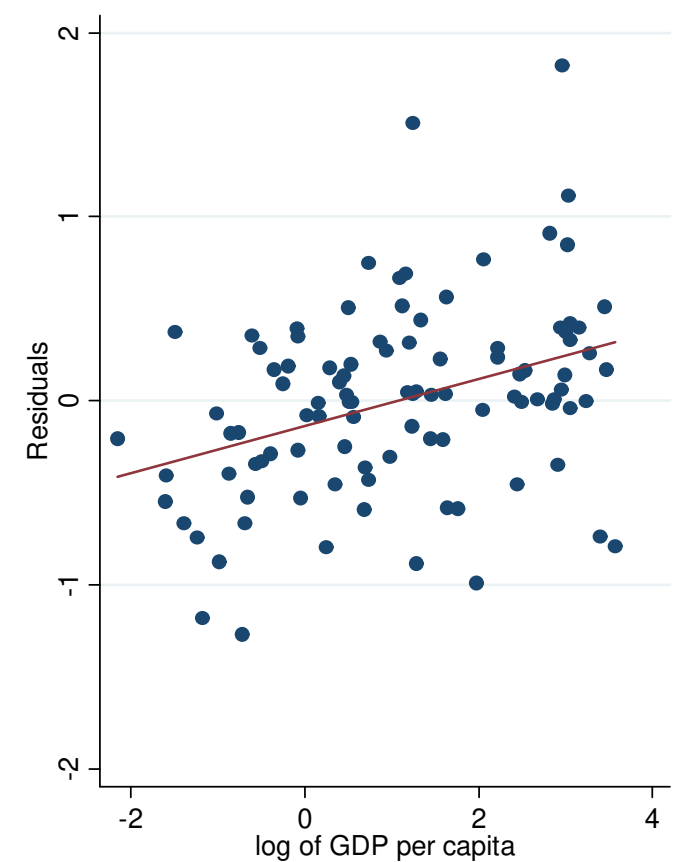

- Residuals Fitted values

slope is 0.13

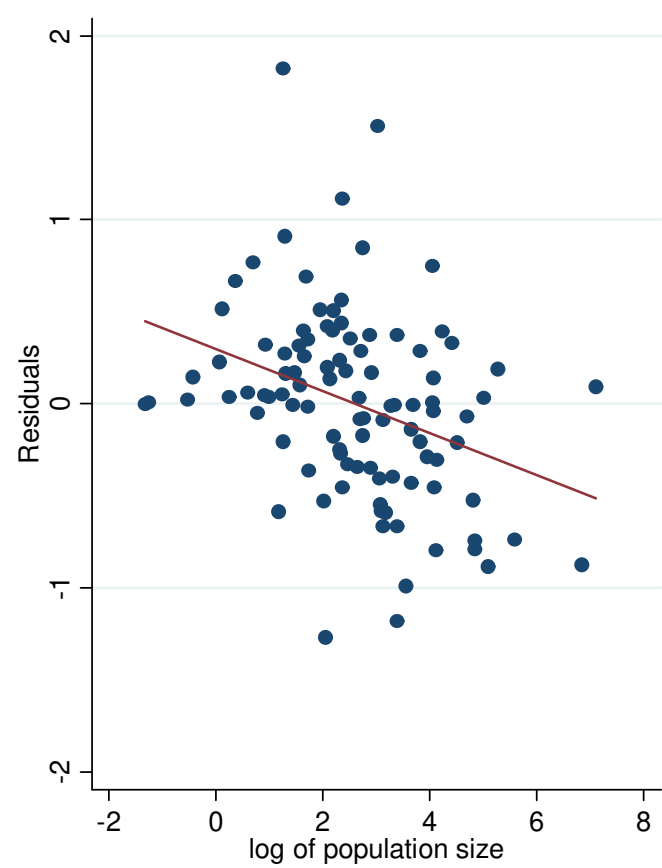

- Residuals $\longrightarrow$ Fitted values slope is -0.11 
Table 13: List of Countries

\begin{tabular}{|c|c|c|}
\hline Country name & GDP per capita $(2000 \mathrm{US} \$)$ & GDP (2000US\$ billion) \\
\hline " United States & $\begin{array}{l}29942 \\
\end{array}$ & 7972.80 \\
\hline Japan & 35439 & 4445.37 \\
\hline Germany & 21073 & 1720.46 \\
\hline United Kingdom & 21160 & 1232.58 \\
\hline France & 19990 & 1156.29 \\
\hline Italy & 17565 & 998.50 \\
\hline China, Hong Kong & 777 & 941.32 \\
\hline Canada & 20170 & 592.06 \\
\hline Brazil & 3613 & 583.91 \\
\hline Spain & 12056 & 474.85 \\
\hline Mexico & 4892 & 445.85 \\
\hline Korea Republic & 9159 & 413.01 \\
\hline India & 372 & 346.57 \\
\hline Australia & 18267 & 330.12 \\
\hline Netherlands & 20427 & 315.81 \\
\hline Argentina & 7184 & 250.26 \\
\hline Russian Federation & 1618 & 239.71 \\
\hline Switzerland & 31614 & 222.60 \\
\hline Belgium, Luxemburg & 20672 & 218.01 \\
\hline Sweden & 23374 & 206.42 \\
\hline Austria & 21088 & 167.72 \\
\hline Turkey & 2666 & 164.60 \\
\hline Indonesia & 827 & 159.38 \\
\hline Norway & 32214 & 140.45 \\
\hline Denmark & 26599 & 139.06 \\
\hline Poland & 3411 & 131.63 \\
\hline Greece & 11445 & 121.71 \\
\hline Thailand & 2086 & 120.01 \\
\hline Venezuela & 5120 & 112.85 \\
\hline Finland & 18899 & 96.54 \\
\hline Israel & 17246 & 95.63 \\
\hline Portugal & 9196 & 92.21 \\
\hline Iran & 1409 & 83.07 \\
\hline Colombia & 2092 & 80.04 \\
\hline
\end{tabular}


Table 13: List of Countries (continued)

\begin{tabular}{|c|c|c|}
\hline Country name & GDP per capita $(2000 \mathrm{US} \$)$ & GDP (2000US\$ billion) \\
\hline Egypt & 1278 & 77.51 \\
\hline Malaysia & 3471 & 71.47 \\
\hline Singapore & 19359 & 68.23 \\
\hline Pakistan & 515 & 63.00 \\
\hline Philippines & 913 & 62.59 \\
\hline Chile & 4295 & 61.82 \\
\hline Ireland & 16799 & 60.62 \\
\hline Czech Republic & 5100 & 52.69 \\
\hline Peru & 1976 & 47.13 \\
\hline Algeria & 1662 & 46.96 \\
\hline NewZealand & 12635 & 46.41 \\
\hline Nigeria & 363 & 39.54 \\
\hline Romania & 1742 & 39.50 \\
\hline Hungary & 3812 & 39.37 \\
\hline Bangladesh & 289 & 36.54 \\
\hline Ukraine & 672 & 34.60 \\
\hline Kuwait & 19048 & 34.33 \\
\hline Morocco & 1160 & 30.66 \\
\hline Uruguay & 5786 & 18.62 \\
\hline Syrian Arab Republic & 1181 & 17.26 \\
\hline Slovak Republic & 3174 & 17.03 \\
\hline Oman & 7749 & 16.83 \\
\hline Kazakhstan & 1023 & 16.18 \\
\hline Guatemala & 1589 & 15.89 \\
\hline Croatia & 3337 & 15.58 \\
\hline Slovenia & 7828 & 15.58 \\
\hline Ecuador & 1335 & 15.21 \\
\hline Lebanon & 4245 & 14.82 \\
\hline Tunisia & 1651 & 14.79 \\
\hline Dominican Republic & 1694 & 13.58 \\
\hline Bulgaria & 1564 & 13.14 \\
\hline SriLanka & 704 & 12.77 \\
\hline Costa Rica & 3608 & 12.54 \\
\hline
\end{tabular}


Table 13: List of Countries (continued)

\begin{tabular}{|c|c|c|}
\hline Country name & GDP per capita (2000US\$) & GDP (2000US $\$$ billion) \\
\hline Kenya & 417 & $\begin{array}{l}11.42 \\
\end{array}$ \\
\hline Uzbekistan & 500 & 11.39 \\
\hline ElSalvador & 2006 & 11.30 \\
\hline Belarus & 920 & 9.38 \\
\hline Lithuania & 2561 & 9.30 \\
\hline Panama & 3470 & 9.27 \\
\hline Sudan & 307 & 9.06 \\
\hline Coted'Ivoire & 596 & 8.93 \\
\hline Jamaica & 3241 & 8.04 \\
\hline Cameroon & 568 & 7.99 \\
\hline Cyprus & 11870 & 7.73 \\
\hline Tanzania & 249 & 7.43 \\
\hline Jordan & 1723 & 7.23 \\
\hline Yemen Rep. & 465 & 7.22 \\
\hline Zimbabwe & 606 & 7.15 \\
\hline Paraguay & 1488 & 7.14 \\
\hline Bolivia & 948 & 7.09 \\
\hline Iceland & 25489 & 6.83 \\
\hline Angola & 544 & 6.70 \\
\hline Bahrain & 11170 & 6.45 \\
\hline Trinidad and Tobago & 5037 & 6.40 \\
\hline Latvia & 2364 & 5.95 \\
\hline Dem.Rep. Congo & 116 & 5.26 \\
\hline Honduras & 921 & 5.13 \\
\hline Gabon & 4737 & 5.00 \\
\hline Nepal & 200 & 4.34 \\
\hline Uganda & 203 & 4.32 \\
\hline Estonia & 2986 & 4.29 \\
\hline Bahamas & 14477 & 4.06 \\
\hline Ghana & 225 & 4.03 \\
\hline Senegal & 424 & 3.84 \\
\hline Azerbaijan & 488 & 3.75 \\
\hline Mauritius & 3064 & 3.44 \\
\hline
\end{tabular}

